\title{
MICROVASCULAR FREE TISSUE TRANSFER OF THE RECTUS ABDOMINIS MUSCLE IN DOGS
}

\author{
by
}

Earl F. Calfee III (Trey)

Thesis submitted to the Faculty of the Virginia Polytechnic Institute and State University

is partial fulfillment of the requirements for the degree of

\author{
Master of Science \\ in \\ Veterinary Medical Science
}

Approval Committee:

Chair: Otto I. Lanz, D.V.M., Diplomate A.C.V.S.

Robert B. Duncan Jr., D.V.M., Ph.D., Diplomate A.C.V.P.

Richard V. Broadstone, D.V.M., Ph.D., Diplomate A.C.V.A.

$\overline{\text { Robert A. Martin, D.V.M., Diplomate A.C.V.S. and A.B.V.P. }}$

March 1, 2002

Blacksburg, VA

Keywords: Microvascular, Rectus Abdominis, Dogs, Tissue Transfer

Copyright 2002, Earl F. Calfee III (Trey) 


\section{MICROVASCULAR FREE TISSUE TRANSFER OF THE RECTUS ABDOMINIS MUSCLE IN DOGS \\ by}

\section{Earl F. Calfee III}

(ABSTRACT)

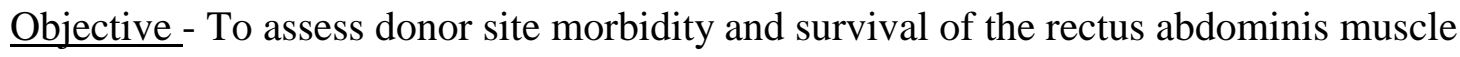
with an overlying skin graft after free tissue transfer to a medial femorotibial defect in dogs.

Study Design - Experimental study

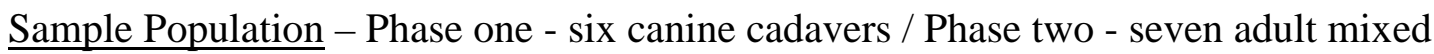
breed dogs

Methods - Phase one - The rectus abdominis muscle was removed from cadavers, muscular and vascular dimensions were recorded and angiography was performed. Phase two - Muscular transfer was performed through anastomosis of the caudal epigastric vasculature to the saphenous vasculature. Transferred tissues were evaluated on postoperative days three, six, 10, and 13. Animals were examined daily until euthanasia between postoperative days 31 and 42. Postmortem angiograms were performed and tissues collected for histopathologic evaluation.

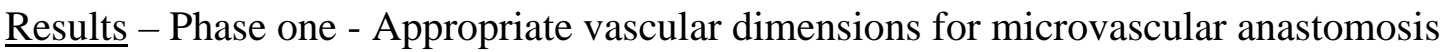
were confirmed and surgical technique perfected. Phase two - Muscular excision produced minimal donor site morbidity. All muscles survived after microvascular transfer and angiography confirmed vascular patency. All skin grafts survived with one graft undergoing partial necrosis.

Conclusions - The rectus abdominis muscle can be successfully transferred to a medial femorotibial defect and serve as a bed for acute skin grafting. No significant donor site morbidity is associated with its removal. 
Clinical Relevance - Microvascular free tissue transfer of the canine rectus abdominis muscle has not been previously described. This technique provides an alternative for repair of appropriate wounds. Additional studies are needed to define its utility in clinical patients. 


\section{TABLE OF CONTENTS}

\begin{tabular}{|c|c|c|}
\hline \multicolumn{2}{|l|}{ Abstract } & _II \\
\hline Introduction / L & Literature Review & 1 \\
\hline \multicolumn{2}{|c|}{ Indications for free tissue transfer } & 1 \\
\hline \multicolumn{2}{|c|}{ Previously transferred tissues - veterinary } & 2 \\
\hline \multicolumn{2}{|r|}{ Superficial cervical flap } & 3 \\
\hline \multicolumn{2}{|r|}{ Medial saphenous flap } & 3 \\
\hline \multicolumn{2}{|r|}{ Latissimus dorsi flap } & 4 \\
\hline \multicolumn{2}{|r|}{ Carpal pad flap } & 4 \\
\hline \multicolumn{2}{|r|}{ Omental pedicle flap } & 4 \\
\hline \multicolumn{2}{|c|}{ Muscular versus cutaneous coverage } & 5 \\
\hline \multicolumn{2}{|c|}{ Requirements for free tissue transfer candidates } & -7 \\
\hline \multicolumn{2}{|c|}{ Vascular patterns of muscles } & -7 \\
\hline \multicolumn{2}{|c|}{ New vascular classification for canine rectus abdominis muscle } & 9 \\
\hline \multicolumn{2}{|c|}{ Previous studies involving canine rectus abdominis } & 10 \\
\hline \multicolumn{2}{|c|}{ Human rectus abdominis free tissue transfer } & 10 \\
\hline \multicolumn{2}{|c|}{ Study objectives } & 11 \\
\hline \multicolumn{2}{|c|}{ Materials and Methods } & 12 \\
\hline \multicolumn{2}{|l|}{ Phase 1} & 12 \\
\hline \multirow{2}{*}{\multicolumn{2}{|c|}{$\begin{array}{l}\text { Muscular excision and vascular isolation } \\
\text { Angiograms }\end{array}$}} & 12 \\
\hline & & 13 \\
\hline \multicolumn{2}{|l|}{ Phase 2} & 14 \\
\hline \multicolumn{2}{|r|}{ Muscular excision and vascular isolation } & -15 \\
\hline \multicolumn{2}{|r|}{ Preparation of recipient site } & 16 \\
\hline \multicolumn{2}{|r|}{ Vascular anastomosis } & 17 \\
\hline & Closure & 18 \\
\hline
\end{tabular}


Bandaging and epidural catheters 18

Post-operative monitoring___ 19

Euthanasia, angiograms and necropsies _ 20

Results__ 21

Phase $1 \_21$

Phase $2 \_21$

Donor and recipient site evaluations___ 22

Angiograms__ 24

Histopathology__ 25

Discussion__ 26

Rectus abdominis anatomy___ 26

Advantage/disadvantages of canine rectus abdominis___ 26

Donor site closures _ 27

Skin graft morbidity___ 28

Post-operative monitoring___ 29

Anticoagulant therapy___ 31

Tissue cosmesis __ 33

Conclusions/Future Research__ 35

References__ 37

Figures 43

Normal canine rectus abdominis anatomy____ 43

Femorotibial defect__ 44

Phase 1 angiogram__ 45

Day 3 bandage changes___ 46

Day 6 bandage changes __ 47

Day 10 bandage changes__ 48

Skin grafts at study conclusion__ 49 
Distal skin graft necrosis__ 50

Traumatic distal graft necrosis___ 51

Incisional bruising _ 52

Seroma formation

Phase 2 angiograms _ 54

Histopathologic muscle atrophy___ 55

Distal skin graft necrosis__ 56

Tables__ 57

Muscular, vascular and recipient site dimensions __ 57

Vita_ 58 


\section{Introduction/Literature Review}

Distal extremity and oral defects present some of the most difficult reconstructive challenges for veterinary surgeons. These anatomic regions lack redundant local tissues and second intention healing of wounds in these body regions is often not possible because of the limited ability of peripheral tissues to undergo contraction. If possible, second intention healing often produces a poor cosmetic outcome and tissues that are susceptible to repeated trauma. Wound repair of distal extremity and oral cavity defects therefore often involves transfer of tissues from distant sites where redundant tissues can be found. Traditionally, this has involved open wound management in preparation for skin grafting. Microvascular free tissue transfer allows acute one stage repair of extensive wounds of the distal extremities and oral cavity with excellent cosmesis and a potentially better functional outcome. Free tissue transfer has the potential to shorten the length of hospitalization because days to weeks of open wound management are unnecessary. In people, free tissue transfer techniques have been shown to shorten unemployment periods and the duration of hospitalization following repair of severe tibial fractures ${ }^{1}$. This has in turn led to lower hospitalization costs and increased patient productivity following these major surgical procedures.

Microvascular free tissue transfer is based on the concept of angiosomes, which are definable regions of tissue perfused by a single nutrient artery and vein. This concept was initially applied with reconstructive procedures based on axial pattern flaps. In the 1980's, several axial pattern flaps were developed for repair of large skin defects in dogs

2-4. Examples include the caudal superficial epigastric, omocervical, thoracodorsal, and deep circumflex iliac axial pattern flaps ${ }^{2,5,6}$. Axial pattern flaps are useful in reconstruction of certain cutaneous defects in dogs and cats. They are, however, limited by dependence on preservation of an intact vascular pedicle. This limitation prevents their use for repair of wounds in the most distal aspects of the limbs and facial region. 
A vascular leash on the other hand does not limit microvascular free tissue transfers. This in turn allows tissue movement to distant recipient sites. Additionally, microvascular free tissue transfer reliably produces viable tissues. This has been documented in both human and veterinary medicine. Fowler, et al retrospectively evaluated outcomes following free tissue transfers in 57 consecutive cases involving two veterinary institutions ${ }^{7}$. Tissues transferred using microvascular techniques included muscle, bone, skin, and footpads. Fifty-three of 57 procedures were successful. Only inexperience of the assistant surgeon and use of the latissimus dorsi muscle flap were associated with increased flap failure. Khouri, et al prospectively evaluated surgical outcome following free tissue transfer in people ${ }^{8}$. This study described outcomes in greater than 450 consecutive patients at over 20 institutions. An overall $96 \%$ success rate for viable tissue transfer was reported. Sixty variables were evaluated for their effect on outcome. Four factors were associated with a higher incidence of post-operative vascular thrombosis. These included the use of interpositional vein grafts, free tissue transfer into previously irradiated or chronic wounds and muscle flaps covered by meshed skin grafts. Both studies concluded that successful free tissue transfer was primarily dependent on the experience level of the primary and assistant surgeons.

Examples of autogenous tissues transferred using microvascular free tissue techniques in veterinary medicine include skin, bone, omentum, muscle, footpads, and various combinations of these tissues ${ }^{7,9-12}$. In 1986, Fowler et al performed the first documented free tissue transfers in veterinary medicine ${ }^{13}$. This involved orthotropic transfer of the superficial cervical skin flap in eight dogs. In this study, the periphery of the superficial cervical angiosome was sharply incised and undermined to the base of the vascular pedicle. The superficial cervical artery and vein were then isolated, transected and microvascular anastomosis performed. The flaps survived in six of eight dogs. In 1987, Miller et al described the successful microvascular transfer of the superficial cervical free flap in a dog following traumatic injury to the forelimb ${ }^{14}$. Later that same 
year Fowler, et al reported successful free tissue transfer of the superficial cervical flap in six clinical cases ${ }^{13}$. The superficial cervical flap was successfully transferred to the rear limb in four dogs and to the forelimb in two dogs.

Between 1988 and 1996 multiple experimental studies were performed which involved free tissue transfer of bone, foot pads or muscle ${ }^{11,15-17}$. They were performed almost exclusively at the University of Saskatchewan under the direction of David Fowler. In these studies, angiosomes of various tissues were initially defined through angiography and viability was later confirmed in research animals following heterotropic transfer.

Several studies were performed based on the angiosome of the superficial cervical vasculature. Initially the vascular supply to the trapezius muscle was defined. Angiography revealed that the prescapular branch of the superficial cervical artery supplied the entire cervical portion of the trapezius muscle as well as its overlying skin ${ }^{18}$. This musculocutaneous composite flap was then transferred successfully in three of four research dogs to a medial femorotibial defect ${ }^{16}$. In 1993, the potential viability of an osteomusculocutaneous free flap using the cervical portion of the trapezius muscle, its overlying skin and the scapular spine was defined ${ }^{15}$. This study revealed that viability of the scapular spine was maintained with preservation of superficial cervical vascular pedicle following detachment of the spine from the scapular body and transection of all other soft tissue attachments.

Between 1996 and 1997, Degner et al published three papers involving the use of microvascular free tissue transfer. Initially the angiosome of the medial saphenous vasculature was defined through angiography. The medial saphenous fasciocutaneous free flap was then successfully transferred to a forelimb defect in six consecutive research $\operatorname{dogs}{ }^{19}$. Medial saphenous fasciocutaneous or myocutaneous free flaps were then successfully transferred in eight clinical cases ${ }^{20}$. The myocutaneous flaps incorporated the distal one half of the caudal head of the sartorius muscle. One-hundred percent tissue 
viability was produced in all eight dogs. Free tissue transfer of the transverses abdominis muscle was then reported in a two-phase study ${ }^{10}$. Phase one defined the perfusion pattern of the muscle and described the dimensions of the phrenicoabdominal artery and vein, which supplied the cranial one half of the muscular body. In phase two, the myoperitoneal flap was successfully used in the repair of a traumatically induced canine oronasal fistula.

In 1996, Nicoll et al described the transfer of the latissimus dorsi free muscle flap in a group of research cats ${ }^{21}$. This study described the thoracodorsal vascular pedicle and its distribution to the latissimus dorsi muscle. Heterotropic and orthotropic transfers of the feline latissimus dorsi muscle were then performed. Muscular viability following heterotropic transfer was confirmed in two of three cats. Complete viability was produced in four of four cats following orthotropic transfer. The authors concluded that the cranial one half of the feline latissimus dorsi muscle is a viable option for free tissue transfer. The 66 percent survival rate was below what is normally reported for canine free tissue transfers but the population sample was too small to determine significance.

In 1997, Fowler and Moens published two papers on the use of a carpal footpad free flap in reconstruction of canine weight bearing surfaces ${ }^{22,23}$. The carpal pad blood supply was described through cadaveric angiograms in order to define the feasibility of microvascular transfer ${ }^{23}$. The carpal pad flap was then successfully transferred in three clinical cases ${ }^{22}$. Surgical revisions were needed in all animals to maintain appropriate weight bearing forces on the transferred tissues and only partial closure of donor sites was possible. All donor sites healed uneventfully through second intention.

In 1999, Roa et al described the survival of a free omental pedicle flap to a canine medial femorotibial defect ${ }^{12}$. The benefits of the abundant omental vasculature and long arterial and venous pedicle length are discussed. Seven omental flaps were transferred in five dogs with only two flaps surviving. Flaps were evaluated through angiography, nuclear scintigraphy and histopathology. Failure of two flaps was attributed to self- 
inflicted trauma from the research dogs. The other flap failures were primarily attributed to a lack of microvascular surgical experience by the investigators.

In 2001, Lanz et al described the effects of epidural lidocaine administration on blood flow through the medial saphenous fasciocutaneous free flap ${ }^{24}$. Lidocaine epidurals were of theoretical benefit because of vasodilatory effects on peripheral tissues. The authors found no increase in free flap blood flow but did see a decline in systemic blood pressures. Administration of lidocaine epidurally was therefore not recommended during free tissue transfer procedures.

It is evident from this literature review that the depth of experience with veterinary free tissue transfer is limited. It is however interesting to find that success rates for human and veterinary free tissue transfers are indistinguishable and that surgical outcomes in both fields are primarily dependent on surgeon ability and experience. This is promising for veterinary medicine and makes free tissue transfer a realistic and feasible option for veterinary patients.

In the past few years attention has been focused on the different capabilities of muscle versus skin in wound healing following transfer into compromised wound beds. From the above literature review we find that four muscles have been transferred using free tissue transfer techniques in the veterinary literature. These include the trapezius, latissimus dorsi, caudal head of the sartorius and the transverses abdominis $10,16,20,21$.

Muscle has an inherently rich blood supply, which has been shown to increase local tissue oxygen tension as well as facilitate delivery of antibiotics and components of the immune system to devascularized wounds ${ }^{25}$. This quality has made microvascular transfer of muscle a mainstay in the treatment of chronic osteomyelitis in people ${ }^{26,27}$. Transplanted muscle also promotes healing of concurrent orthopedic injuries through enhancement of periosteal blood supply ${ }^{28-30}$ and increases the strength of early bony union in devascularized fracture models ${ }^{30}$. In addition, transferred muscle provides a 
physical barrier for compromised recipient tissues and can serve as a bed for acute skin grafting ${ }^{26,27}$.

Very little scientific data exists in the veterinary literature comparing the benefits of muscular and cutaneous transfers into devascularized wounds. Much of the human literature however involves the use of animal models to compare the effects of muscular and cutaneous coverage. Porter et al recently compared the effects of devascularized cortical bone coverage with a free muscle flap versus a cutaneous axial pattern flap in the $\operatorname{dog}^{31}$. They found no statistical differences between treatment groups when comparing cortical blood flow, cortical bone porosity, intracortical new bone production and maximum depth of new periosteal bone formation. There was a trend towards greater periosteal bone formation beneath muscle than skin but the difference was not significant. The authors recognized one major fault in their study design. They did not adequately prevent endosteal revascularization from proximal and distal aspects of the fracture model. This interfered with their ability to detect differences in periosteal blood flow contribution between the muscle and skin coverage groups. In light of the fact that multiple previous studies have documented the superiority of muscular coverage in the above capacities the results of this study are called into question.

Based on current knowledge levels, it is not clear what qualities make muscle superior to skin in the promotion of wound healing. Gosain et al compared the effect of muscular and cutaneous coverage on inhibition of bacterial inoculum growth ${ }^{25}$. Their work revealed that blood flow supplied by muscle coverage as opposed to cutaneous coverage was significantly greater 24 hours following surgery. The superiority of muscular blood flow was however temporary with a trend of increasing blood flow in the skin coverage group over the six days following individual surgical procedures. Blood flow underlying the cutaneous flaps eventually surpassed that under the muscular flaps. Throughout the study however bacterial inoculum counts were significantly less in the muscle coverage group. The authors theorized that the superiority of muscular blood 
flow in the first 24 hours following tissue elevation prevented bacterial tissue colonization. The authors also observed that muscle was more firmly adherent to the bacterial inoculum chambers with greater tissue ingrowth than skin. They hypothesized that this quality of tissue adherence and ingrowth was in part responsible for muscles ability to resist infection better than skin. This concept is also alluded to in Porter's canine study even though differences in tissue adhesion between cutaneous and muscular coverage groups were not noted ${ }^{31}$. The authors state the need for overlying tissues to develop intimate contact with devascularized beds in order to stimulate angiogenesis and resultant vascular ingrowth. Their study however was not designed to test differences in adhesion properties between skin and muscle coverage groups. Muscle's qualities of tissue ingrowth and malleability may inevitably be responsible for its ability to promote tissue healing more effectively than skin.

An individual muscle must fulfill certain anatomic requirements prior to consideration for use in free tissue transfer. Muscles must have an expendable function, be easily accessible, have a reliable vascular pedicle, and produce minimal donor site morbidity following removal ${ }^{32}$. If a muscle to be used in free tissue transfer does not have an expendable function then it must have surrounding musculature to perform its function following removal from the donor site. Additional requirements include a vascular pedicle length of at least $10.0 \mathrm{~mm}$, arterial and venous diameters of at least 0.5 $\mathrm{mm}$, and an appropriate vascular distribution ${ }^{21,33,34}$.

Currently, there are five defined vascular patterns for muscles. Type one muscles receive blood flow from one major vascular pedicle and the entire muscle can be transferred based on that pedicle. Type two muscles have one or more dominant pedicles entering at the muscle's insertion or origin with additional minor pedicles entering the muscular body. Transfer of type two muscles can be performed based on the major vascular pedicle following ligation of the minor pedicles. Type three muscles have two major vascular pedicles that each supplies approximately $50 \%$ of the muscular blood 
flow. Transfer of type three muscles can be based on either of the major pedicles but a portion of the muscle will routinely die if the entire muscle is transferred. Type four muscles have no major vascular pedicle but are perfused by several minor pedicles. Type four muscles therefore have very limited application in free tissue transfer. Type five muscles have one major vascular pedicle but receive additional blood supply from minor segmental vessels. The entire muscle will survive if either the major vascular pedicle or the segmental blood supply is maintained.

The canine rectus abdominis muscle is described as having a type three vascular pattern ${ }^{35}$. It primarily receives blood flow from two major vascular pedicles, the cranial epigastric artery and vein and the caudal epigastric artery and vein. (See Figure 1) Terminal branches of the deep circumflex iliac artery and vein coursing with the medial branches of spinal nerves T13-L3 enter the muscle's lateral margin and provide segmental perfusion. Based on the original description of type three vascular patterns a portion of the rectus abdominis muscle would be expected to die if transfer of the entire muscle were based on a single vascular pedicle.

Previous studies by Degner et al demonstrated that perfusion of the entire canine rectus abdominis muscle is maintained following transection of the caudal epigastric blood supply ${ }^{36}$. This study revealed that approximately two-thirds of the abdominal portion of the rectus abdominis muscle is perfused by the caudal vascular pedicle. Contrast angiograms revealed anastomotic "choke vessels" between the cranial and caudal muscular blood supplies. These choke vessels support perfusion of the entire muscle following ligation of the caudal vascular pedicle. Scintigraphic findings in this same study found no difference in quantitative blood flow between control rectus abdominis muscles and contralateral muscles following transection of the caudal vascular pedicle. Based on these results survival of the entire muscle was predicted following division of the caudal epigastric pedicle. This was confirmed experimentally in five of six dogs with a cranially based axial rotation of the entire rectus abdominis muscle and its 
overlying cutaneous paddle ${ }^{35}$. Transfer of the overlying skin was unsuccessful in five of six dogs but the entire rectus abdominis muscle survived in all but one dog. Because viability of the entire muscle has been documented based on a cranial vascular pedicle transfer and 2/3 of the muscle is perfused by the caudal epigastric vasculature, I felt the entire muscle should remain viable following a caudally based transfer.

This predicted viability calls into doubt the categorization of the rectus abdominis muscle as a type three muscle. Solano et al proposed an additional classification for the canine semitendinosus muscle, which has a similar vascular pattern to the rectus abdominis muscle ${ }^{37}$. The semitendinosus muscle has two primary vascular pedicles and the entire muscle survives following ligation of either pedicle. They proposed an additional category of type three B or type six for muscles that have two primary vascular pedicles which allow survival of the entire muscle following ligation of either pedicle. The rectus abdominis muscle appears to fall into this category.

The vessels of both the cranial and caudal vascular pedicles of the rectus abdominis muscle are of appropriate diameter and length for use in free tissue transfer. Gregory et al defined the potential use of the canine rectus abdominis, gracilis and latissimus dorsi myocutaneous tissues in free tissue transfer ${ }^{33}$. This study involved peripheral tissue dissection, vascular isolation and fluorescein staining in 15 canine cadavers. Based on the results of this study, the authors concluded that the gracilis and latissimus dorsi myocutaneous flaps were good candidates for free tissue transfer because of adequate vascular pedicle dimensions, easily performed dissection and tissue viability following peripheral dissection. The authors however did not recommend use of the rectus abdominis myocutaneous flap because of unreliable viability of the skin overlying the caudal aspect of the muscle. The cranial and caudal epigastric vascular pedicle dimensions were both of adequate dimensions for use in free tissue transfer but the cranial pedicle was described as being difficult to harvest in dogs with deep thoracic conformations. Transfer of the rectus abdominis muscle in the present study was based 
on the caudal epigastric blood supply because of the reported harvesting difficulties in Gregory's study and the primary role of the caudal epigastric artery and vein in perfusion of the rectus abdominis muscle.

Successful removal of the canine rectus abdominis muscle from the ventral abdomen without postoperative morbidity has been previously described by Degner et al. This was demonstrated during transfer of the cranial rectus abdominis muscle pedicle flap with its overlying caudal superficial epigastric skin flap ${ }^{35}$. The authors did not specifically intend to describe post-operative morbidity following removal of the rectus abdominis muscle from the ventral abdomen but noted that none of the dogs developed abdominal wall hernias following surgery.

Free tissue transfer of the rectus abdominis muscle is reported in the human literature $^{38-41}$. This muscle is consistently and effectively used in reconstruction of lower extremity defects in people. The reported benefits of its use include minimal donor site morbidity, a reliable vascular pedicle with dimensions that facilitate microvascular anastomosis, and an ability to be contoured into distal extremity defects ${ }^{39}$. The pedicle length in people is reported to exceed the mean pedicle length of other free tissue transfer candidates and therefore often prevents the need for interpositional "bridging" vein grafts. Vein grafts were recently associated with an increased risk of intra-operative and post-operative vascular thrombosis in human free tissue transfers ${ }^{8}$. A lengthy vascular pedicle is therefore quite beneficial in minimizing failure of free tissue transfers. Minimal donor site morbidity is one of the most beneficial qualities of the human rectus abdominis free flap. In people the muscle is harvested laparoscopically through a limited inguinal incision ${ }^{41}$. This approach allows harvesting of up to 100 percent of the muscle with a scar that is easily covered by undergarments. Cosmesis undoubtedly plays a larger role in people than veterinary patients, as donor site morbidity is rarely an issue following veterinary free tissue transfers. 
Microvascular free tissue transfer of the canine rectus abdominis muscle has not previously been reported in the veterinary literature. Therefore, the objectives of this study were to show that the rectus abdominis muscle could be successfully transferred to a defect created on the medial aspect of the canine femorotibial region using microvascular surgical techniques. Additionally we hypothesized that the muscle would be a suitable bed for acute meshed skin grafting, and that removal of the muscle from the ventral body wall would be associated with minimal morbidity. Previous veterinary research has shown that the canine rectus abdominis muscle meets the basic requirements for free tissue transfer candidates including minimal donor site morbidity, an appropriate vascular angiosome and adequate vascular dimensions. We were therefore confident that free tissue transfer of the rectus abdominis muscle would produce reliably viable tissue. 


\section{Materials and Methods}

The study was divided into two phases. Phase one was performed on canine cadavers and defined the vascular anatomy and muscular dimensions of the rectus abdominis muscle. The surgical technique for vascular isolation and muscular excision was also perfected in phase one. Phase two was performed on live dogs and determined the feasibility of transferring the rectus abdominis muscle to a defect created on the medial aspect of the femorotibial region.

\section{Phase 1}

Phase one was performed using six canine cadavers weighing between 20 and $40 \mathrm{~kg}$ that were previously used in either student teaching laboratories or continuing education seminars at the Virginia-Maryland Regional College of Veterinary Medicine. Heparin sodium (100 units/kg)(Elkins Sinn Inc., Cherry Hill, NJ) was administered intravenously prior to euthanasia. The skin, subcutaneous tissues and linea alba were incised along midline from the level of the xiphoid to the cranial border of the pubis. Lateral dissection was performed along the caudal extent of the incision to identify the lateral margin of the rectus abdominis muscle and the superficial inguinal ring. The fascia of the internal and external abdominal oblique muscles was longitudinally incised over the ventral surface of the rectus abdominis muscle beginning at the craniomedial border of the inguinal canal. The ventral fascia overlying the rectus abdominis muscle was then dissected from the ventral muscular surface until it became firmly adherent to the muscle at the first or second tendinous intersections cranial to the pubis. The fascia was then transected and dissection continued along the lateral and medial borders of the rectus abdominis muscle. Laterally, perforating neurovascular bundles were ligated and transected near their entry into the muscle. The muscle was then transected at the level of the xiphoid. Blunt dissection of fascial tissues dorsal to the rectus abdominis muscle allowed lateral 
retraction of the muscle. This facilitated visualization of the caudal epigastric artery and vein entering the caudodorsal muscular surface. The caudal epigastric vasculature was then followed proximally to its origin from the deep femoral artery and vein as the pudendoepigastric arterial and venous trunks. The deep femoral artery and vein were ligated and transected proximal and distal to the origin of their respective pudendoepigastric trunks. These points of vascular transection allowed removal of the caudal epigastric vasculature while maintaining the integrity of the entire pudendoepigastric trunk. This in turn facilitated measurement of the caudal epigastric vascular pedicle length and arterial diameter. The external pudendal artery and vein were ligated and transected distal to their branching from the pudendoepigastric trunk. The muscle was then transected at its insertion along the cranial border of the pubis allowing its removal from the abdomen with an intact vascular pedicle.

After removal of the muscle, a 20 gauge, 1.88-inch over-the-needle intravenous catheter (Angiocath, Becton Dickinson, Sandy, UT) was inserted into the arterial pudendoepigastric trunk. A 3:1 water: barium sulfate suspension (Liquid E-Z-Paque, EZEM Inc., Westbury, NY) was infused using a 12 cc syringe until resistance was felt. The muscles were then refrigerated for 24 hours at minus nine degrees Celsius to allow hardening of the barium infusion.

Twenty-four hours following muscular removal from the ventral abdomen, angiography was performed with a cabinet x-ray system (Faxitron x-ray system-43805N, Hewlett Packard, McMinnville, OR). After angiography was completed, measurements of muscular width, length and thickness were recorded. Arterial pedicle length and base diameter were also determined using calipers. Arterial diameter measurements were taken from the base of the pudendoepigastric trunk as it branched from the deep femoral artery. Pedicle length was measured from the origin of the pudendoepigastric trunk at the deep femoral artery to the entry of the caudal epigastric artery into the rectus abdominis muscle. 


\section{Phase 2}

The Virginia Tech Animal Care Committee approved all animal use in this project. Four female and three male mixed breed dogs were used for the live animal portion of the study. A thorough physical examination, a serum chemistry profile, and a complete blood count were performed on each dog prior to entrance into the study to rule out any systemic disease processes that might interfere with tissue healing after free tissue transfer. Dogs were housed in the research facilities for 10 days prior to initiation of the study to acclimate them to frequent handling and their new environment. Aspirin (81 mg/dog)(Rugby Laboratories, Norcross, GA) was administered orally at 12-hour intervals beginning 24 hours prior to surgery and continuing for 72 hours afterwards. Animals were pre-medicated with intramuscular injections of acepromazine maleate $(0.3$ $\mathrm{mg} / \mathrm{kg})($ Fort Dodge Animal Health, Fort Dodge, IO), morphine sulfate (0.25 $\mathrm{mg} / \mathrm{kg})$ (Elkins-Sinn, Cherry Hill, NJ) and atropine $(0.3 \mathrm{mg} / \mathrm{kg})($ Phoenix Pharmaceuticals, Inc., St. Joseph, MO). Anesthetic induction was achieved with intravenous sodium thiopental (10 mg/kg)(Pentothal, Abbott Laboratories, North Chicago, IL). After orotracheal intubation anesthesia was maintained with isoflurane in $100 \%$ oxygen (Isoflo, Abbott Laboratories, North Chicago, IL). Intravenous cefazolin (22mg/kg) (Apothecan, Princeton, NJ) was administered after anesthetic induction and at two-hour intervals during the procedure. Intravenous fluids (Lactated Ringers Solution, Baxter Healthcare Corporation, Deerfield, IL) were administered at a rate of $22 \mathrm{ml} / \mathrm{kg} / \mathrm{hr}$ during surgery and a warm air blanket (Bair Hugger, Augustine Medical, Eden Prarie, MN) was used to maintain body temperature during surgery and recovery from anesthesia.

After they were anesthetized, all of the dogs had a surgical clip and aseptic skin preparation of their ventral abdomen and left femorotibial region. The left rear limb was circumferentially clipped from the mid-metatarsal region to the dorsal midline. Removal 
of the rectus abdominis muscle and creation of the rear limb defect were performed simultaneously by two separate surgical teams.

The skin was incised on the ventral midline from the xiphoid to the cranial border of the pubis. In male dogs a parapreputial incision was created. The initial skin incision was deepened to the level of the linea alba. Subcutaneous tissues were undermined laterally to identify the left superficial inguinal ring. The ventral fascia overlying the rectus abdominis muscle was incised along the muscular midline from the inguinal canal cranially to the level of cranial muscular transection. Adherent fascia was sharply dissected from the ventral surface of the muscle to expose the lateral and medial muscular margins. This allowed visualization of the entire ventral muscular surface. Dorsally adherent fascia was bluntly dissected from the muscle. Laterally perforating, segmental neurovascular bundles were ligated using hemoclips (Weck Closure Systems, Research Triangle Park, NC) and transected near their entry into the muscle. The muscle was then transected cranially. Hemoclips (Weck Closure Systems, Research Triangle Park, NC) were used to control hemorrhage encountered during cranial transection of the rectus abdominis muscle. The point of cranial muscular transection was determined by the proximal to distal measurements of the femorotibial defect. The excised segment of rectus abdominis muscle was however intentionally shorter than the femorotibial defect to allow for muscular stretching after transfer into the defect. A $10 \mathrm{~mm}$ section of adherent ventral rectus fascia was maintained on the cranial border of the muscle to facilitate suture purchase at the recipient site. Prior to cranial and caudal muscular transection, measurements of the length and width of the rectus abdominis muscle were recorded.

The muscle was reflected laterally allowing visualization of the caudal epigastric artery and vein as they entered the caudodorsal surface of the muscle. The muscle was transected at its insertion along the cranial border of the pubis. Surrounding adventitial tissues were meticulously dissected from the caudal epigastric vasculature to the level of 
vascular branching from the deep femoral artery and vein. The external pudendal artery and vein were ligated and transected near their origin from the pudendoepigastric trunk. Measurements of the caudal epigastric pedicle length, as well as the arterial and venous pedicle base diameters, as described in phase one, were determined and recorded at this time. The muscle was then covered with a moistened laparotomy sponge while awaiting transfer into the cutaneous defect created on the medial aspect of the femorotibial region.

Prior to skin incision at the recipient site, a sterile marking pen was used to outline the dimensions of the proposed femorotibial cutaneous defect. The defect started at the level of the mid-femur and ended just proximal to the tarsocrural joint and involved an estimated 50 percent of the limb's circumference. (See Figure 2) Defect dimensions were recorded and the skin was sharply incised. Subcutaneous tissues were dissected from the underlying dermis and the saphenous artery and medial saphenous vein identified. A curvilinear skin incision originating at the cranioproximal margin of the defect and extending proximally was made. The skin edges were undermined to allow additional visualization of the saphenous vascular pedicle. The previously excised skin was then prepared for use as a full thickness meshed skin graft by removal of all subcutaneous tissues and meshing with a No. 15 scalpel blade.

Adventitial tissue was removed from the saphenous artery and medial saphenous vein in preparation for transection and eventual anastomosis. After the adventitia was removed the arterial and venous diameters were measured and recorded. The saphenous artery and medial saphenous vein were then ligated with hemoclips at the level of the mid femur and microvascular vessel clamps were placed proximal to the hemoclips. The vessels were transected between the microvascular clamps and the hemoclips.

The caudal epigastric artery and vein were similarly ligated with hemoclips and divided immediately distal to where the vessels branched from the deep femoral artery and vein. A microvascular clamp was placed on the vein distal to the hemoclips prior to 
venous transection to prevent passive hemorrhage from the vein during arterial anastomosis. The rectus abdominis muscle was then removed from the abdomen.

The muscle was placed into the femorotibial defect with the ventral muscular surface positioned superficially and the caudal muscular border placed proximally. This positioning allowed approximation of the saphenous and caudal epigastric vascular pedicles. Stay sutures were placed in the proximal margins of the muscle to inhibit movement during vessel anastomosis. The caudal epigastric artery and the saphenous artery were positioned in a microvascular-approximating clamp (Accurate Surgical and Scientific Instruments, Westbury, NY). The vascular lumens were flushed with heparinized saline (10 units $/ \mathrm{ml}$ ) and additional adventitial tissue was removed from vessel ends with microvascular dissection scissors (ASSI, Westbury, NY). An end-toend arterial anastomosis was performed with the aid of an operating microscope using 10/0 nylon suture (Braun Surgical, Emmenbrucke, Germany) on a 100 um taper needle in a simple interrupted pattern. Venous anastomosis was performed with a $2.0 \mathrm{~mm}$ polyethylene coupling ring (Medical Co. Alliances, Inc, Park City, UT). Two percent lidocaine (Phoenix Pharmaceuticals Inc., St. Joseph, MO) was applied topically to the arteries and veins to minimize vasospasm.

After arterial and venous anastomoses, the microvascular clamps were removed and the vessels were evaluated for patency. Patency was confirmed by visualization of a flash of blood crossing the venous anastomotic site, return of a reddish-pink coloration to the muscle, and arterial pulse transmission distal to the arterial anastomosis. Total ischemic time was then recorded.

After the confirmation of patency, the peripheral borders of the rectus abdominis muscle were sutured to the surrounding subcutaneous tissues with $4 / 0$ glycomer 60 (Monosyn, Braun Surgical, Melsungen, Germany) in a simple continuous pattern. The proximal curvilinear incision was closed with 4/0 glycomer 60 in an interrupted subcuticular pattern. The previously prepared full thickness meshed skin graft was 
placed over the transferred rectus abdominis muscle and sutured to the margins of the rear limb defect with a combination of interrupted and continuous suture patterns using 4/0 glycomer 60 .

The abdominal incision was closed in four layers in females and five layers in males. The lateral fascial margins of the internal and external abdominal oblique musculature were apposed to the medial fascial margins using 0 polydioxanone (PDS, Ethicon Inc., Johnson and Johnson, Somerville, NJ) in a simple interrupted pattern. In male dogs, a two layer subcutaneous closure was performed using 3/0 glycomer 60 (Monosyn, Braun Surgical, Melsungen, Germany) in a simple continuous pattern. In females, a single subcutaneous layer was placed. Bites were taken intermittently into deep fascial tissues to obliterate dead space and prevent seroma formation. The skin margins were apposed using 3/0 glycomer 60 in a subcuticular pattern. Final skin closure was accomplished with either 3/0 monofilament nylon (Dermalon, Sherwood/Davis and Geck, St. Louis, MO) in a cruciate pattern or skin staples (Davis and Geck, St. Louis, MO).

After surgery a non-adherent dressing (Adaptic, Johnson and Johnson, Arlington, TX) was coated with triple antibiotic ointment (Qualitest Pharmaceuticals, Inc., Huntsville, AL) and placed over the skin graft. Several layers of cast padding and compressive wrap were then applied circumferentially around the limb, followed by a fiberglass cylindrical cast (Delta Lite"s", Johnson and Johnson, Raynham, MA). The cast was cut along its cranial and caudal surfaces producing medial and lateral halves. The cast was then covered with another wrap (Vetwrap, 3M Animal Care Products, St. Paul, MN and Elasticon, Johnson and Johnson, Arlington, TX). An epidural catheter (Arrow International Inc., Reading, PA) was placed in all dogs for delivery of Duramorph to provide analgesia after surgery.

Epidural morphine (Duramorph) $(0.1 \mathrm{mg} / \mathrm{kg})$ injections were administered every eight hours until the time of catheter removal. Morphine sulfate $(0.25 \mathrm{mg} / \mathrm{kg})$ (Elkins- 
Sinn Cherry Hill, NJ) was also available for intramuscular injection if the dogs appeared persistently painful after epidural morphine administration. The catheters were removed at the time of the first bandage change three days after surgery. Animals were given cephalexin (22 mg/kg PO) (Teva Pharmaceuticals, Sellersville, PA) three times daily for 10 days following surgery. Daily evaluations of bandage condition, abdominal incisional condition, appetite, general attitude, urination, and defecation were noted. Bandages were changed three, six, and 10 days after surgery. Prior to bandage changes, animals were sedated with intravenous acepromazine maleate $(1.0 \mathrm{mg} / \mathrm{dog}$ ) (Fort Dodge Animal Health, Fort Dodge, IO). During bandage changes, photographs of the skin grafts and donor sites were taken. Viability of the skin grafts was subjectively evaluated using tissue color, muscular bleeding induced by bandage removal, and superficial temperature as criteria. Grafts were cleaned with nolvasan scrub on days six and 10 prior to rebandaging. On day six, the medial aspect of the bivalve cast was removed and animals were maintained in a lateral splint. On day 12 , the lateral splints were removed and the limbs were left uncovered for the remainder of the study.

Animals were housed in the clinical research facilities for the remainder of the study and evaluated twice daily until euthanasia was performed with an intravenous injection of pentobarbital sodium/phenytoin solution $(1.0 \mathrm{ml} / 10$ \#) (Beuthanasia-D Special, Schering-Plough Animal Health, Union, NJ). Animals were euthanatized between four and one-half and six weeks after surgery.

After the dogs were killed, the skin and subcutaneous tissues overlying the femoral artery were incised. Subcutaneous tissue dissection was continued to the level of the femoral artery. An 18 gauge, 1.88-inch over-the-needle intravenous catheter (Angiocath, Becton Dickinson, Sandy, UT) was introduced into the femoral artery proximal to the branching of the saphenous artery. The catheter was directed into the saphenous artery and the distal tip of the catheter advanced to a point proximal to the arterial anastomosis. The catheter was secured in the vessel with multiple circumferential 
sutures and flushed with heparinized saline. Seven milliliters of intravenous iothalamate sodium (Conray 400, Mallinckrodt inc., St. Louis, MO) were injected into the catheter and radiographs (lateral and craniocaudal views) were made of the femorotibial regions. Determinations of arterial and venous anastomotic patency and muscular perfusion were assessed from the resultant angiograms.

After angiograms were made, gross necropsies were performed and representative samples collected from the recipient and donor sites of all dogs. The meshed skin graft and underlying rectus abdominis muscle were incised peripherally and undermined beginning distally up to the level of the arterial and venous anastomoses. A single ligature was placed around the saphenous artery and medial saphenous vein proximal to the anastomoses and the vessels were transected proximal to the ligature. The entire rectus abdominis muscle flap was placed on cardboard in a fully expanded state and immersed in a solution of 10 percent neutral buffered formalin. The cutaneous tissues of the donor site were then incised and sharp dissection continued to the level of the abdominal body wall closure. The cranial two-thirds of the body wall closure were excised in entirety and placed in the formalin solution.

The following day samples were collected from the preserved tissues. A single full thickness cross-sectional sample was removed from the previously excised donor site closure at a point just cranial to the umbilicus. Samples were removed from three separate regions of the recipient site. One sample was obtained from the area of the venous and arterial anastomoses. Longitudinal and cross-sectional samples were collected from both the proximal and distal portions of the skin grafts and underlying rectus abdominis muscles. The samples were then routinely processed, embedded in paraffin, sectioned and stained with hematoxylin and eosin. Microscopic slides were evaluated for changes in the muscular and cutaneous tissues. Samples of normal muscle from the contralateral rectus abdominus muscle were collected from the donor site for comparison purposes. 


\section{Results}

\section{Phase 1}

The results of the phase one cadaveric angiographic studies confirmed that the caudal epigastric artery and vein perfused approximately two-thirds of the length of the rectus abdominis muscle. The caudal epigastric artery and vein entered the caudodorsal surface of the muscle and coursed cranially near the midline of the muscular body. Prior to vessel termination, three to five medial and lateral vascular branches were visualized exiting the main arterial trunk. Lateral branches were generally more prominent than medial branches. Anastomotic communications between the caudal and cranial epigastric angiosomes were visualized at the cranial termination of the caudal epigastric artery. (See Figure 3) In all six dogs, the arterial and venous pudendoepigastric trunks originated from the deep femoral vasculature. The pudendoepigastric trunk then divided into the external pudendal and caudal epigastric vasculature. Mean width, length, and thickness $(+/-\mathrm{SD})$ of the rectus abdominis muscles $(\mathrm{n}=6)$ were $41+/-2 \mathrm{~mm}, 205+/-33 \mathrm{~mm}$ and 7 $+/-2 \mathrm{~mm}$, respectively. The mean vascular pedicle length was $29+/-9 \mathrm{~mm}$. The mean diameter of the caudal epigastric arteries at the base of the pudendoepigastric trunk was 2 $+/-1 \mathrm{~mm}$.

Muscular dissection consistently revealed three to four irregular transverse tendinous intersections, which were adherent to the ventral surface of the rectus abdominis muscle. The ventral rectus fascia became progressively more adherent to the muscle as cranial dissection was performed. Four to five laterally perforating segmental neurovascular bundles were consistently encountered during muscular dissection.

\section{Phase 2}

Hematology tests and the results of general physical examination, performed prior to entrance into phase two of the study, were within normal limits in all dogs. The dogs 
weighed between 16.4 and $27.7 \mathrm{~kg}$. The mean length and width of the excised rectus abdominis muscles $(\mathrm{n}=7)$ were $225+/-48 \mathrm{~mm}$ and $55+/-2 \mathrm{~mm}$, respectively. Mean length of the caudal epigastric vascular pedicle $(\mathrm{n}=7)$ was $28+/-2 \mathrm{~mm}$. The mean diameter of the caudal epigastric artery and vein $(\mathrm{n}=7)$ were $1.9+/-0.2 \mathrm{~mm}$ and $2.9+/-$ $0.5 \mathrm{~mm}$, respectively. The mean diameters of the saphenous artery and medial saphenous vein $(n=7)$ at the level of vessel anastomosis were $2.1+/-0.4 \mathrm{~mm}$ and $3.1+/-0.6 \mathrm{~mm}$, respectively. The mean medial femorotibial wound $(n=7)$ length and width were $258+/-$ $10 \mathrm{~mm}$ and $66+/-6 \mathrm{~mm}$, respectively. (See Table 1) Mean rectus abdominis ischemic time $(n=7)$ was $40+/-6$ minutes.

In five of seven dogs, the pudendoepigastric trunk was visualized branching from the deep femoral artery and vein. Prior to entry of the caudal epigastric artery and vein into the caudodorsal border of the rectus abdominis muscle, the pudendoepigastric trunk divided into the external pudendal and caudal epigastric arteries and veins. Two of seven dogs had deviations from the aforementioned anatomy. These two dogs did not have a pudendoepigastric trunk. Instead, the external pudendal artery and vein originated directly from the deep femoral vasculature. This did not interfere with vascular isolation, transection, or anastomosis but was noted during vascular dissection.

Epidural catheters were removed three days after the surgical procedure. No significant complications occurred with their use. Two dogs were treated with intermittent urinary catheterization for urine retention, which resolved within 48 hours.

The meshed skin grafts survived in all seven dogs. One hundred percent survival, however, only occurred in six dogs. On day three (See Figure 4), all skin grafts were discolored with multifocal areas of pale pink, red, and dark purple. Mild to moderate bruising was visualized along the cutaneous margin peripheral to the skin grafts. Pink to red bleeding muscle was clearly visible through the fenestrations of the skin grafts in all dogs. All grafts appeared moderately edematous in comparison to surrounding tissues with the distal aspect of the grafts being most affected. 
On day six, cutaneous bruising peripheral to the skin grafts had resolved in all dogs (See Figure 5). The skin grafts developed a more homogenous pink to red coloration. The rectus abdominis muscle was no longer clearly visualized through the fenestrations of the skin grafts in most dogs. Three of seven skin grafts (numbers 2, 4, and 5) had one to three areas of superficial epidermal necrosis that were approximately one centimeter in diameter. The skin grafts continued to appear moderately edematous and raised in comparison with adjacent skin margins.

At day ten, the skin grafts had similar coloration to surrounding skin but were slightly erythematous. The edema had decreased and the skin grafts were only slightly raised in comparison with surrounding skin. Most skin graft fenestrations had closed and bleeding granulation tissue was visualized protruding from the fenestrations that had not closed. (See Figure 6)

At four weeks, the skin grafts showed no discoloration as compared to surrounding normal tissues. Minimal fenestrations were evident and early hair growth was visible on most skin grafts. At the conclusion of the study, four and one-half to six weeks after surgery, the grafts had a similar appearance to surrounding normal skin and moderate hair growth was visualized on all skin grafts. Hair density varied between individual dogs. Fenestration of the skin grafts was not readily apparent. The skin grafts were only minimally raised in comparison to surrounding tissues (See Figure 7).

Three days after surgery, one dog (number 6) had an area of clear demarcation along the distal aspect of its skin graft with uniform pale discoloration distal to the line of demarcation. (See Figure 8) At day six, the distal portion of the skin graft appeared somewhat desiccated and dark purple in color. At day 10, a line of black demarcation indicating skin necrosis was visualized. This area was not debrided and by day 21 the area of necrosis had sloughed. Four weeks after surgery epithelial margins of the cutaneous defect had advanced to nearly close the underlying defect. At the conclusion 
of the study, a defect of less than $5 \mathrm{~mm}$ in length was present at the distal end of the skin graft.

Twenty days after surgery, one dog (number 3) self traumatized the distal onethird of the skin graft. (See Figure 9) The damage was superficial and did not expose underlying muscle. The area was cleaned daily with dilute nolvasan but not bandaged. At the end of the study, the traumatized area had decreased in size and peripheral epithelium was advancing to close the epidermal defect.

Donor sites healed without complications in all dogs. Three dogs (numbers 3, 4, and 5) developed moderate bruising along the cutaneous margins of the abdominal incisions, which was attributed to the aspirin therapy. (See Figure 10) Dog number 4 developed a seroma along the most dependent portion of its abdominal incision that resolved with no specific treatment within 10 days after surgery. (See Figure 11) At necropsy, visual inspection and digital palpation confirmed the integrity of all abdominal closures.

At the conclusion of the study, angiography confirmed venous and arterial anastomotic patency in all seven dogs. All venous anastomoses were narrowed to the internal diameter of the anastomotic coupler $(2.0 \mathrm{~mm})$. Minimal evidence of arterial anastomotic constriction was evident on three of seven angiograms. Arterial constriction was visualized as a gradual luminal narrowing as opposed to a distinct luminal irregularity. In all dogs, three to five cranial and caudal vascular branches were visualized distal to the level of the anastomoses. The cranial vascular branches were generally larger with more extensive branching than the caudal branches. This asymmetry in vascular distribution is consistent with the asymmetrical branching visualized in phase one angiograms, where lateral vascular branches were generally larger than medial branches. The angiograms of three dogs (numbers 3, 4, and 7) revealed the development of vascular anastomoses with peripheral tissues. Anastomotic vessels were visualized 
between the vascular beds of the transferred rectus abdominis muscles and venous structures of the lateral saphenous vasculature (See Figure 12).

Histological evaluation confirmed muscular viability after microvascular free tissue transfer in all seven dogs. All dogs had evidence of mild to moderate muscle fiber atrophy. Hypertrophy and rounding of nuclei were visible both peripherally and occasionally centrally in individual muscle fibers of all dogs. Occasional centrally located nuclear rows were present in longitudinal sections of the transferred muscles (See Figure 13). All samples collected at necropsy from the contralateral rectus abdominis muscles revealed normal skeletal muscle with no evidence of atrophy.

In the two dogs that developed epidermal ulceration viable muscle was present beneath the ulcerative beds. Marked acanthosis and hyperkeratosis were visualized at the margins of the ulcers in both dogs and there was maintenance of viable dermis and adnexa overlying the supporting muscular beds. (See Figure 14) Regions of fibroplasia and fibrovascular connective tissue joined the superficial and deep muscular margins to the pre-existing connective tissue of the femorotibial defects and overlying meshed skin grafts in all dogs. 


\section{Discussion}

The rectus abdominis is a long, flat-paired muscle located on the ventral midline that originates from the first costal cartilages and inserts on the cranial border of the pubis. It is encased within the rectus sheath that is composed of the insertional tendons of the internal abdominal oblique, external abdominal oblique, and transversus abdominis muscles. The rectus sheath does not surround the most caudodorsal aspect of the rectus abdominis muscle. Instead, a thin layer of the transversalis fascia and peritoneum covers this surface. The abdominal portion of the rectus abdominis muscle receives innervation from the medial branches of spinal nerves T13-L3. (See Figure 1) ${ }^{36}$

The rectus abdominis muscle has several beneficial anatomic qualities when used in free tissue transfer. First, its long rectangular shape is ideal for placement in wounds of the distal extremities. This is in comparison to the triangular shape of the trapezius muscle and the broad rectangular shape of the latissimus dorsi muscle. Second, complete enclosure of the rectus abdominis muscle within the rectus sheath allows its precise removal from the abdomen without associated subcutaneous tissues. This, in turn, produces less bulk after transfer and facilitates its use as a bed for acute skin grafting. Third, the consistent thickness of the rectus abdominis muscle throughout its length produces excellent cosmetic results. Finally, the peritoneal covering of the muscle's caudodorsal border makes the rectus abdominis a candidate for use as a specialized myoperitoneal flap as is reported in people ${ }^{38}$.

One potential disadvantage of the rectus abdominis muscle is its relatively narrow dimensions. This may prevent its use in covering defects involving greater than 50 percent of the circumference of the distal extremities. The trapezius muscle with its triangular shape may be more appropriate for repair of wider defects. Another potential disadvantage of the rectus abdominis muscle for free tissue transfer is its relatively short vascular pedicle, as compared to reported pedicle lengths of other muscles used in 
veterinary surgery. The prescapular branch of the superficial cervical artery and vein supplying the trapezius muscle and the phrenicoabdominal artery and vein supplying the transversus abdominis muscle are $44+/-10 \mathrm{~mm}$ and $46.7+/-5.0 \mathrm{~mm}$ in length, respectively ${ }^{10,18}$. The mean length of the caudal epigastric vascular pedicle, $28+/-2$ $\mathrm{mm}$, as measured in phase two of this study easily exceeds the minimal length requirements for microvascular transfer but may be limiting in situations where a longer vascular pedicle would be needed.

The overall length of the rectus abdominis muscle (mean $-22.5 \mathrm{~cm}$ ) may however negate the limitations of the relatively short vascular pedicle. This length should allow anastomosis of the rectus vascular pedicle with donor vessels that are outside the area of recipient site injury. This in turn should allow use of the rectus abdominis muscle in free tissue transfer where extensive damage of recipient site vascular beds has occurred and anastomosis must be performed away from the primary defect.

All donor site closures healed without major complications. Muscle excision did require entrance into the abdominal cavity but in an otherwise stable animal this would not be expected to produce increased morbidity as compared to muscle excisions from other body regions. Bruising, which was attributed to aspirin therapy, was noted around the abdominal incisions in three dogs and a dependent seroma formed in one dog. Aspirin predisposed to incisional bruising through inhibition of the cyclooxygenase pathway.

Seroma formation is commonly reported, if not expected, with excision of muscular or myocutaneous donor tissues from the scapular region in dogs and cats ${ }^{15,21}$. Nicoll et al reported seroma formation in seven of seven cats following orthotropic and heterotropic transfer of the latissimus dorsi muscle flap ${ }^{21}$. Philibert et al, reported seroma formation in four of four dogs following free tissue transfer of the trapezius musculocutaneous flap ${ }^{15}$. Finally, Degner reported seroma formation and partial donor site dehiscence in two of six medial saphenous fasciocutaneous free flaps ${ }^{19}$. In 
comparison to the morbidity associated with tissue harvest from other canine free tissue transfer donor sites, harvesting of the rectus abdominis is associated with minimal morbidity.

The full thickness, distal skin graft necrosis seen on one dog is not easily explained. The most common etiologies for skin graft failure include excessive graft movement, sub-graft hematoma or seroma formation and infection. These causes however seem unlikely in the dog of our study because the pelvic limbs were bandaged in all dogs for approximately two weeks following individual surgical dates and no evidence of infection, seroma or hematoma was seen in this dog prior to skin necrosis visualization.

Excessive bandage pressure or inadequate subcutaneous tissue removal are other possible etiologies for distal necrosis in this dog. Attempts were made to produce even pressure throughout the bandaged limbs in all dogs. The most distal aspects of the grafts were however located just proximal to the tarsus. This is known to be a natural region of bandage constriction because of relatively reduced limb circumference ${ }^{42}$. Bandaging of the distal tibia produces a focal "tourniquet effect" if additional padding is not provided. This in turn predisposes to distal extremity ischemic injuries. It is possible in our study that the skin grafts under these areas were predisposed to excessive bandage pressure and this could be responsible for the distal graft necrosis in this dog. We are however unable to explain viability in the rest of the distal skin grafts with the above theory.

Inadequate removal of subcutaneous tissues could also have been responsible for the aforementioned graft necrosis. Meshed skin graft viability is dependent on nutrition from underlying tissues through plasmatic imbibition. This process involves bathing of the deep graft surface with serum from the recipient tissue bed. Excessive subcutaneous graft tissues interfere with this process. Graft revascularization through inosculation and vascular ingrowth is also inhibited by inadequate subcutaneous tissue removal from the deep surface of skin grafts. Revascularization begins as early as 48 hours following skin 
graft placement. Capillary rich granulation tissue produces vascular sprouts, which enter the deep surface of skin grafts. If sprouting capillaries enter pre-existing vascular channels vessel growth is facilitated because of minimal tissue resistance. Inadequate removal of graft subcutaneous tissues interferes with revascularization and therefore is a plausible explanation for distal graft failure in the one dog of our study.

Intensive post-operative monitoring was not performed following free tissue transfer in this study because of the logistical difficulties. In people, flap monitoring is a priority and has been the subject of extensive research attempting to determine the ideal monitoring modality ${ }^{43-48}$. Intensive monitoring has proven essential in people because of a reported post-operative thrombosis rate of approximately $10 \%{ }^{8}$. In addition, salvage rates as high as $70 \%$ have been reported following re-operation for thromboses flaps. The success of a second exploratory surgery is however largely dependent on rapid recognition of vascular compromise. Early re-operation minimizes the deleterious effects of temporary tissue ischemia and the so-called "no reflow" phenomenon.

Monitoring methods can be divided into two primary categories; direct vascular pedicle blood flow measurements and determinations of tissue perfusion. Ultrasonic doppler blood flow probes have been one of the most commonly used instruments to determine blood flow across vascular anastamoses ${ }^{43,47,48}$ These instruments determine blood flow through detection of changes in sound wave frequencies reflected from moving blood cells. Within the last 10 years implantable Doppler probes have been developed that allow measurement of blood flow in buried muscle flaps ${ }^{48}$. Probes are easily placed and removed through simple retraction preventing the need for an additional surgery for probe removal. Probes are however expensive, have the potential to traumatize vasculature anastomoses, can provide inaccurate information if displaced and will not accurately read when subjects are moving ${ }^{43}$. Their use has not been evaluated in veterinary free tissue transfer patients. 
Duplex Doppler transcutaneous ultrasonography has also been used in people to monitor vascular pedicle patency. This technique uses a combination of gray scale ultrasound imaging and Doppler flow measurements. Vessels as small as $1.0 \mathrm{~mm}$ in diameter can be visualized and arterial and venous flow can be differentiated. This method however does not allow continuous monitoring and is highly dependent on the skills of the ultrasonographer. Instrumentation for its usage is also very expensive. Other methods of determining vascular patency include electromagnetic flowmetry and arterial thermometry ${ }^{47}$.

Two common methods of determining tissue perfusion include dermofluorometry and radioisotope scanning. Fluoroscein staining has historically been considered the best means of identifying inadequate flap perfusion ${ }^{47}$. This originally involved the use of a Wood's lamp to visualize areas of tissue fluorescence. Dermofluorometry differs from traditional fluorescein staining through the use of a dermofluorometer to quantify surface fluorescence. The dermofluorometer requires small volumes of fluorescein and allows sequential measurements of increased fluorescein following repeated injections. This method however underestimates tissue viability and cannot be used for continuous monitoring because of a delay in tissue drug removal when perfusion decreases. Fluoroscein injection using the traditional Wood's lamp is associated with an unacceptably high rate of allergic reactions in people ${ }^{44}$. Dermofluorometry virtually eliminates these reactions but still underestimates tissue viability by as much as $37 \%{ }^{46}$. Radioisotope scanning has frequently been used to determine tissue viability and fluid flow in both human and veterinary medicine ${ }^{12,17,49-51}$. It is reliable in defining perfusion and tissue viability but cannot be used for continuous monitoring. It also involves radioisotopes, which require special licensure for use and isolation facilities. This methodology is most useful in determining viability of vascularized free bone transfers ${ }^{17,48,51}$. Other methods of monitoring tissue perfusion and viability including pulse oximetry, skin surface thermometry, impedence, tissue $\mathrm{pH}$ and hematocrit 
measurements, magnetic resonance imaging, radioisotopic washout, thermal clearance, reflection spectrophotometry, photoplethysmography, transcutaneous oxygen monitoring and interstitial fluid pressure monitoring have been described in people but are beyond the scope of this discussion.

Even with the development of numerous sophisticated and expensive techniques to monitor tissue viability the most reliably accepted method continues to be subjective flap evaluation by a member of the surgical team. The aforementioned monitoring techniques have been developed to allow continuous monitoring by less experienced personnel. This in turn allows notification of the surgical team when potential flap compromise occurs. In veterinary medicine flap monitoring is made difficult by the fact that surgical sites must be protected from animal mutilation and movement is often uncontrollable. This frequently necessitates covering transferred tissues with protective bandages or casts. In our study, we did not attempt to monitor the rectus flaps because of concern for potential tissue compromise from repeated bandage changes, exposed tissues, or adjacent monitoring instrumentation.

In the current study both topical and systemic anticoagulants were used. Topical heparinized saline was used intraoperatively because of its inhibitory effects on thrombin and coagulation factor $\mathrm{Xa}$ and its promotion of antithrombin 3 activity ${ }^{52}$. Aspirin was also used in the perioperative period in order to block the production of thromboxane A2 that is known to stimulate platelet aggregation. Other anticoagulants that have been routinely used in human reimplantations and elective microsurgical procedures include Dextran, dipyridamole, pentoxifylline, chlorpromazine, streptokinase, urokinase and tissue plasminogen activator ${ }^{53}$. Their use is more aggressively administered with reimplantation procedures for traumatic extremity amputations than for elective free tissue transfers because of extensive vascular damage and subendothelial collagen exposure associated with re-implantation procedures. 
Extensive human research has been performed attempting to define the ideal topical or systemic anticoagulants ${ }^{52}$. There is no agreement about which agents are ideal but it has been shown that some form of anticoagulant administration is beneficial to the patency rates of experimental microvascular anastomoses ${ }^{52-54}$. Clinical studies are often based on exaggerated subendothelial collagen exposure through extensive endothelium removal, vascular lumen inversion or vascular crushing methods. In these studies antithrombotic agents are clearly beneficial with dramatic differences in patency rates between treatment and control groups ${ }^{52-54}$.

In clinical studies the benefits of anti-thrombotic agents are not so clear. A 1998 prospective clinical study by Khouri found that anti-thrombotic administration had no effect on the overall success rate of free tissue transfers ${ }^{8}$. The authors concluded that use of antithrombotic agents is relatively unimportant in comparison to precise surgical technique. The benefits of peri-operative anticoagulant therapy for re-implantation procedures have on the other hand been documented in the human literature ${ }^{55}$. Salemark et al demonstrated the benefits of anticoagulant therapy in re-implantation procedures but were unable to demonstrate significant benefits of antithrombotic administration for elective free tissue transfers. This most likely reflects differences in the degree of endothelial injury with traumatic reimplantations more closely mimicking experimental models where endothelial damage is significant.

Controversy still exists about the role of antithrombotic agents in successful microvascular free tissue transfers. Antithrombotic therapy appears most beneficial when vascular damage is extensive. Because traumatic extremity reimplantations have not been reported in the veterinary literature antithrombotic therapy most likely plays a minor role at best in veterinary patients. With atraumatic free tissue transfers endothelial damage should be minimal and successful transfer is likely therefore almost entirely dependent on appropriate microvascular technique. General agreement although not universal exists that anticoagulants play a supporting role in the success of free tissue 
transfers. Agreement is however universal that meticulous technique and adequate surgical experience are prerequisites for successful free tissue transfers.

The transferred rectus abdominis muscle with its overlying meshed skin graft produced excellent cosmesis in this study. The muscle conformed well to the femorotibial defect and was not noticeably bulky. Subjectively, a moderate amount of tissue edema was evident immediately after transfer. This was most apparent in the distal aspect of the transferred tissues. Ten to fourteen days later, the thickness of the transferred tissues had decreased and skin grafts were only slightly elevated in comparison to the peripheral skin margin. The time frame required for resolution of edema coincided with the predictable return of lymphatic drainage in tissues transferred by microvascular techniques. This time frame of lymphatic return has been demonstrated in experimental animal models and clinical human patients following limb reimplantations and free tissue transfers ${ }^{49,50}$.

Muscle atrophy seen histologically at the studies conclusion was expected. Denervation atrophy is reported in both the human and veterinary literature after free muscle transfer ${ }^{16,21,35,56,57}$. Atrophy following free tissue transfer is reported to be fiber type specific with preferential atrophy of type- 1 muscle fibers ${ }^{56}$. Increased muscle atrophy is associated with prolonged immobilization and post-operative infection. This quantitative decrease in muscle fiber mass does however not correlate with a decrease in overall thickness of transferred tissues. In people, no statistically significant decrease in overall tissue thickness is reported up to four years after microvascular free tissue transfer of muscles with overlying meshed skin grafts ${ }^{58}$. Muscle transfers have actually been reported to increase in thickness a mean of 2.4 times preoperative measurements by two weeks postoperatively and maintain 1.7 times their original thickness at six weeks ${ }^{58}$. Replacement of muscle fibers with adipose and fibrous tissues may account for the lack of an overall decrease in tissue volume after microvascular free tissue transfer. 
Often with veterinary cutaneous or myocutaneous free tissue transfer the direction of hair growth and hair density are less than ideal because skin orientation is dictated by the position of the vascular pedicle. Acute skin grafting over muscle flaps allows orientation of hair growth to approximate surrounding tissues. Additionally, the skin graft donor site can be selected to minimize visible scar formation and to more closely approximate the qualities of the skin surrounding the recipient site defect. Meshed skin grafting over the transferred rectus abdominis muscle was performed in this study because of the previously mentioned cosmetic benefits and because of documented poor perfusion to the caudal aspects of the cutaneous angiosome overlying the canine rectus abdominis muscle ${ }^{33}$. 


\section{Conclusion}

In conclusion, this study confirmed that the canine rectus abdominis muscle could be successfully transferred to a femorotibial defect using microvascular techniques. Phase one verified that the caudal epigastric vascular pedicle is of appropriate diameter and length for use in free tissue transfer. In phase two, muscular dissection and pedicle isolation were relatively straightforward. Minimal donor site morbidity was associated with removal of the muscle from the ventral abdomen and the transferred rectus abdominis muscle served as a viable bed for acute skin grafting. Further work is needed to demonstrate the reproducible utility of the rectus abdominis muscle for free tissue transfer in clinical cases.

One potential area of future research is in defining the utility of the canine rectus abdominis muscle in oral cavity reconstruction. The canine transverses abdominis muscle has been successfully used in reconstruction of a traumatic canine maxillary defect ${ }^{10}$. Degner et al described the benefits of myoperitoneal reconstruction for oral cavity defects with primary healing of oral mucosa to the transferred peritoneal surface ${ }^{10}$. The human rectus abdominis muscle with its associated peritoneal lining is successfully used in intraoral reconstructive surgery. Mixter et al described five cases of successful intra-oral rectus abdominis myoperitoneal free flap transfer in people ${ }^{38}$. This article briefly describes the benefits of oral myoperitoneal transfers, which again include primary healing of the muscles peritoneal lining with adjacent oral squamous epithelium and resistance of the peritoneal covering to oral and gastric secretions.

The canine rectus abdominis muscles partial peritoneal lining makes it a candidate for use as a myoperitoneal flap in oral reconstructive surgery. The muscle has been successfully used in this fashion in one clinical case at the Virginia-Maryland Regional College of Veterinary Medicine following a traumatic maxillary wound. Prior to free tissue transfer multiple unsuccessful attempts were made using local tissue advancement 
techniques. Final repair was achieved with free tissue transfer of the rectus into the oral cavity. Thus far the use of specialized free tissue transfers in veterinary medicine have been rarely described. With time however such research will inevitably begin to appear in the veterinary literature. 


\section{References}

1. Francel TJ. Improving reemployment rates after limb salvage of acute severe tibial fractures by microvascular soft-tissue reconstruction. Plast Reconstr Surg 1994;93:1028-34.

2. Pavletic MM. Canine axial pattern flaps, using the omocervical, thoracodorsal and deep circumflex iliac direct cutaneous arteries. Am J Vet Res 1981;42:391-406.

3. Kostolich M, Pavletic MM. Axial pattern flap based on the genicular branch of the saphenous artery in the dog. Vet Surg 1987;16:217-22.

4. Henney LH, Pavletic MM. Axial pattern flap based on the superficial brachial artery in the dog. Vet Surg 1988;17:311-7.

5. Pavletic MM. Caudal superficial epigastric arterial pedicle grafts in the dog. Vet Surg 1980;9:103-107.

6. Pavletic MM, Kostolich M, Koblik P, et al. A comparison of the cutaneous trunci myocutaneous flap and latissimus dorsi myocutaneous flap in the dog. Vet Surg 1987;16:283-93.

7. Fowler JD, Degner DA, Walshaw R, et al. Microvascular free tissue transfer: results in 57 consecutive cases. Vet Surg 1998;27:406-12.

8. Khouri RK, Cooley BC, Kunselman AR, et al. A prospective study of microvascular free-f lap surgery and outcome. Plast Reconstr Surg 1998;102:711-21.

9. Basher AW, Fowler JD, Bowen CV, et al. Microneurovascular free digital pad transfer in the dog. Vet Surg 1990;19:226-31.

10. Degner DA, Lanz OI, Walshaw R. Myoperitoneal microvascular free flaps in dogs: an anatomical study and a clinical case report. Vet Surg 1996;25:463-70.

11. Fowler JD, Levitt L, Bowen CV. Microsurgical free bone transfer in the dog. Microsurgery 1991;12:145-50. 
12. Roa DM, Bright RM, Daniel GB, et al. Microvascular transplantation of a free omental graft to the distal extremity in dogs. Vet Surg 1999;28:456-65.

13. Fowler JD, Miller CW, Bowen V, et al. Transfer of free vascular cutaneous flaps by microvascular anastomosis. Results in six dogs. Vet Surg 1987;16:446-50.

14. Miller C. Microvascular distant transfer of a axial-pattern flap in a dog. JAVMA 1987;190:203-204.

15. Philibert D, Fowler JD. The trapezius osteomusculocutaneous flap in dogs. Vet Surg 1993;22:444-50.

16. Philibert D, Fowler JD, Clapson JB. Free microvascular transplantation of the trapezius musculocutaneous flap in dogs. Vet Surg 1992;21:435-40.

17. Szentimrey D, Fowler D, Johnston G, et al. Transplantation of the canine distal ulna as a free vascularized bone graft. Vet Surg 1995;24:215-25.

18. Philibert D, Fowler JD, Clapson JB. The anatomic basis for a trapezius muscle flap in dogs. Vet Surg 1992;21:429-34.

19. Degner DA, Walshaw R, Lanz O, et al. The medial saphenous fasciocutaneous free flap in dogs. Vet Surg 1996;25:105-13.

20. Degner DA, Walshaw R. Medial saphenous fasciocutaneous and myocutaneous free flap transfer in eight dogs. Vet Surg 1997;26:20-5.

21. Nicoll SA, Fowler JD, Remedios AM, et al. Development of a free latissimus dorsi muscle flap in cats. Vet Surg 1996;25:40-8.

22. Fowler J. The microvascular carpal foot pad flap: results in three clinical cases. VCOT 1997; 10:187-191.

23. Moens N. The microvascular carpal foot pad flap: vascular anatomy and surgical technique. VCOT 1997;10:183-186.

24. Lanz OI, Broadstone RV, Martin RA, et al. Effects of epidural anesthesia on microcirculatory blood flow in free medial saphenous fasciocutaneous flaps in dogs. Vet Surg 2001;30:374-9. 
25. Gosain A, Chang N, Mathes S, et al. A study of the relationship between blood flow and bacterial inoculation in musculocutaneous and fasciocutaneous flaps. Plast Reconstr Surg 1990;86:1152-62; discussion 1163.

26. Musharafieh R, Osmani O, Musharafieh U, et al. Efficacy of microsurgical freetissue transfer in chronic osteomyelitis of the leg and foot: review of 22 cases. $J$ Reconstr Microsurg 1999;15:239-44.

27. Anthony JP, Mathes SJ, Alpert BS. The muscle flap in the treatment of chronic lower extremity osteomyelitis: results in patients over 5 years after treatment. Plast Reconstr Surg 1991;88:311-8.

28. Fisher J, Wood MB. Experimental comparison of bone revascularization by musculocutaneous and cutaneous flaps. Plast Reconstr Surg 1987;79:81-90.

29. Richards RR, Schemitsch EH. Effect of muscle flap coverage on bone blood flow following devascularization of a segment of tibia: an experimental investigation in the dog. J Orthop Res 1989;7:550-8.

30. Richards RR, McKee MD, Paitich CB, et al. A comparison of the effects of skin coverage and muscle flap coverage on the early strength of union at the site of osteotomy after devascularization of a segment of canine tibia. J Bone Joint Surg Am 1991;73:1323-30.

31. Porter CD, Fowler JD, Matte GG. A comparison of skin and muscle for cortical revascularization. V.C.O.T. 2000;13:128-134.

32. Fowler J. Reconstructive Microsurgical Applications In: W. a. Wilkins, ed. Current Techniques in Small Animal Surgery. Fourth ed. Baltimore, MD, $1998 ; 607-621$.

33. Gregory CR, Gourley IM, Koblik PD, et al. Experimental definition of latissimus dorsi, gracilis, and rectus abdominus musculocutaneous flaps in the dog. Am J Vet Res 1988;49:878-84. 
34. Fujimaki A, O'Brien BM, Kurata T, et al. Experimental micro-anastomosis of 0.40.5 mm vessels. Br J Plast Surg 1977;30:269-72.

35. Degner DA, Walshaw R, Arnoczky SP, et al. Evaluation of the cranial rectus abdominus muscle pedicle flap as a blood supply for the caudal superficial epigastric skin flap in dogs. Vet Surg 1996;25:292-9.

36. Degner D. The cranial rectus abdominus muscle pedicle flap in the dog. VCOT 1994;7:21-24.

37. Solano M, Purinton PT, Chambers JN, et al. Effects of vascular pedicle ligation on blood flow in canine semitendinosus muscle. Am J Vet Res 1995;56:731-5.

38. Mixter RC, Mayfield K, Dibbell DG, et al. Intraoral reconstruction with a microvascular peritoneal flap [see comments]. Plast Reconstr Surg 1991;88:4527.

39. Reath DB, Taylor JW. Free rectus abdominis muscle flap: advantages in lower extremity reconstruction. South Med J 1989;82:1143-6.

40. Reath DB, Taylor JW. The segmental rectus abdominis free flap for ankle and foot reconstruction. Plast Reconstr Surg 1991;88:824-8; discussion 829-30.

41. Salgado CJ, Orlando GS, Herceg S, et al. Pfannenstiel incision as an alternative approach for harvesting the rectus abdominis muscle for free-tissue transfer. Plast Reconstr Surg 2000;105:1330-3.

42. Anderson DM, White RA. Ischemic bandage injuries: a case series and review of the literature. Vet Surg 2000;29:488-98.

43. Furnas H, Rosen JM. Monitoring in microvascular surgery. Ann Plast Surg 1991;26:265-72.

44. Graham BH, Walton RL, Elings VB, et al. Surface quantification of injected fluorescein as a predictor of flap viability. Plast Reconstr Surg 1983;71:826-33.

45. Khouri RK, Shaw WW. Monitoring of free flaps with surface-temperature recordings: is it reliable? Plast Reconstr Surg 1992;89:495-9; discussion 500-2. 
46. Myers B, Donovan W. An evaluation of eight methods of using fluorescein to predict the viability of skin flaps in the pig. Plast Reconstr Surg 1985;75:245-50.

47. Stepnick DW, Hayden RE. Postoperative monitoring and salvage of microvascular free flaps. Otolaryngol Clin North Am 1994;27:1201-17.

48. Machens HG, Mailaender P, Rieck B, et al. Techniques of postoperative blood flow monitoring after free tissue transfer: an overview. Microsurgery 1994; 15:778-86.

49. Anthony JP, Foster RD, Price DC, et al. Lymphatic regeneration following microvascular limb replantation: a qualitative and quantitative animal study. $J$ Reconstr Microsurg 1997;13:327-30.

50. Khazanchi RK, Rakshit K, Bal CS, et al. Evaluation of lymphatic drainage in free flaps by lymphoscintigraphy: a preliminary study. Br J Plast Surg 1996;49:123-8.

51. Levitt L, Fowler JD, Longley M, et al. A developmental model for free vascularized bone transfers in the dog. Vet Surg 1988;17:194-202.

52. Das SK, Miller JH. Current status of topical antithrombotic agents in microvascular surgery. Microsurgery 1994;15:630-2.

53. Siegel DB. Use of anticoagulants in replantation and elective microsurgery. Microsurgery 1991;12:277-80.

54. Rothkopf DM, Chu B, Bern S, et al. The effect of dextran on microvascular thrombosis in an experimental rabbit model [see comments]. Plast Reconstr Surg 1993;92:511-5.

55. Salemark L. International survey of current microvascular practices in free tissue transfer and replantation surgery. Microsurgery 1991;12:308-11.

56. Kauhanen MS, Salmi AM, von Boguslawsky EK, et al. Muscle fiber diameter and muscle type distribution following free microvascular muscle transfers: a prospective study. Microsurgery 1998;18:137-44. 
57. Schmalbruch H, al-Amood WS, Lewis DM. Morphology of long-term denervated rat soleus muscle and the effect of chronic electrical stimulation. $J$ Physiol 1991;441:233-41.

58. Salmi A, Tukiainen E, Harma M, et al. A prospective study of changes in muscle dimensions following free- muscle transfer measured by ultrasound and CT scanning. Plast Reconstr Surg 1996;97:1443-50. 


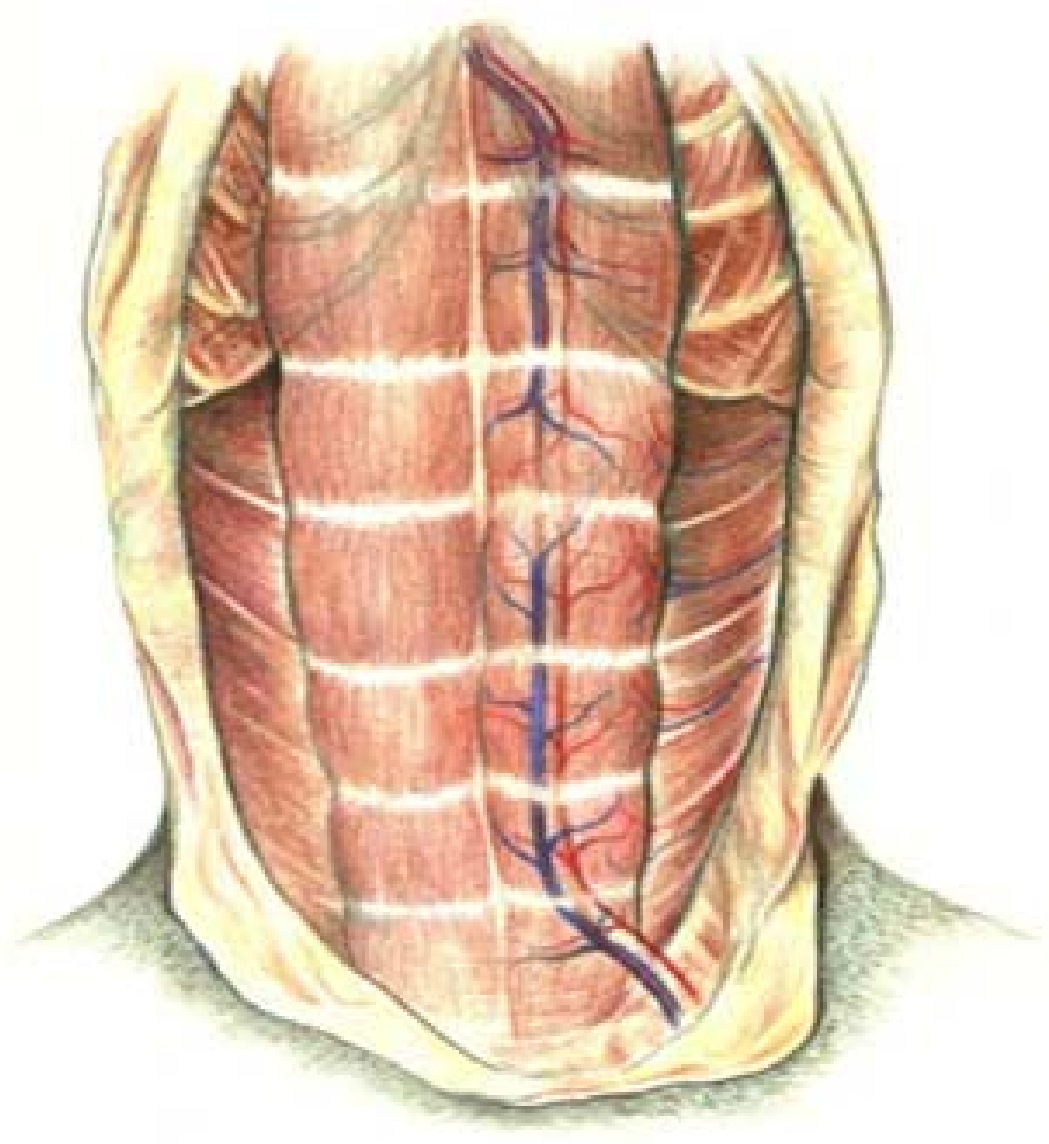

Figure 1 - Normal Canine Rectus Abdominis Anatomy - The muscle receives blood flow from two primary sources, the cranial and caudal epigastric arteries and veins. Additional perfusion is supplied by lateral perforating vessels, which are terminal branches of the deep circumflex iliac artery and vein. The muscle has four to five tendinous intersections, which are points of firm attachment by the rectus abdominis sheath. The rectus sheath completely surrounds the muscle and is composed of the insertional tendons of the internal abdominal oblique, external abdominal oblique and transversus abdominis muscles. 


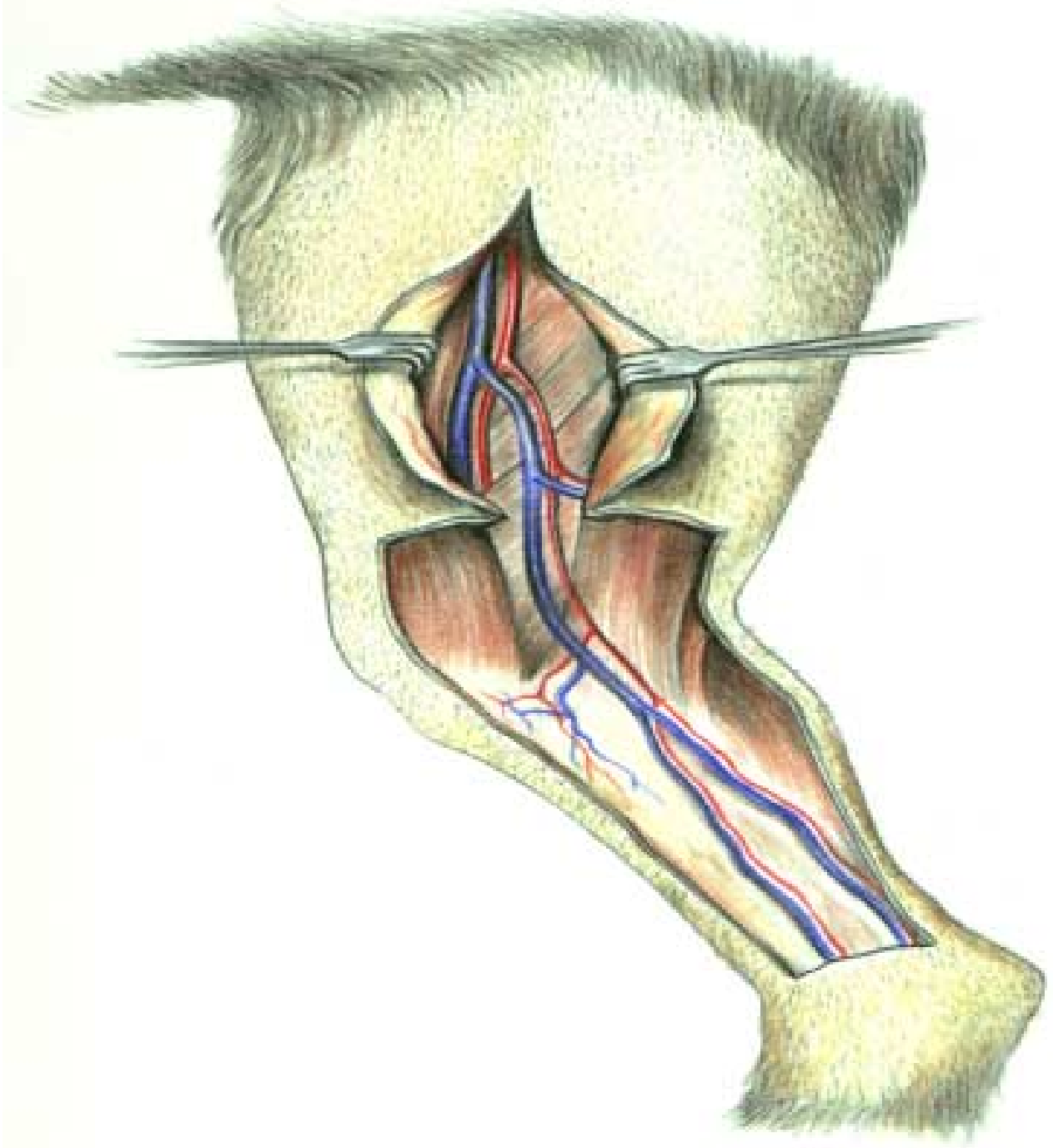

Figure 2 - Femorotibial Defect - Cutaneous tissues were removed from the distal aspect of the femur to the level of the distal tibia and included approximately $1 / 2$ the circumference of the limb. An additional proximal incision was made to allow visualization of the recipient site vasculature. 


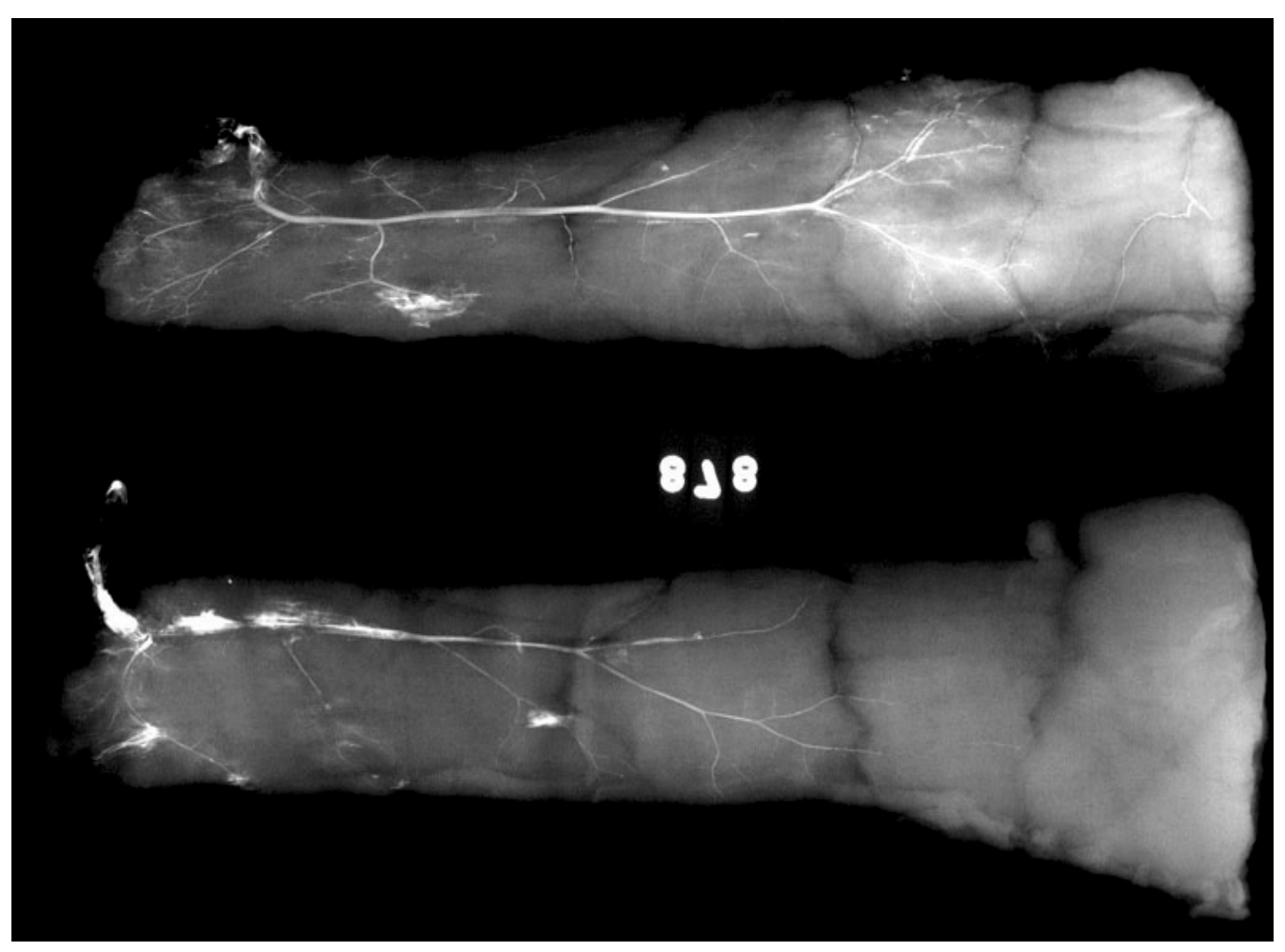

Figure 3 - Phase One Angiograms - Angiograms confirmed that the caudal epigastric artery and vein perfused approximately two-thirds of the length of the rectus abdominis muscle. Prior to vessel termination, three to five medial and lateral vascular branches were visualized exiting the main arterial trunk. Lateral branches were generally more prominent than medial branches. Anastomotic communications between the caudal and cranial epigastric angiosomes were visualized at the cranial termination of the caudal epigastric artery. 


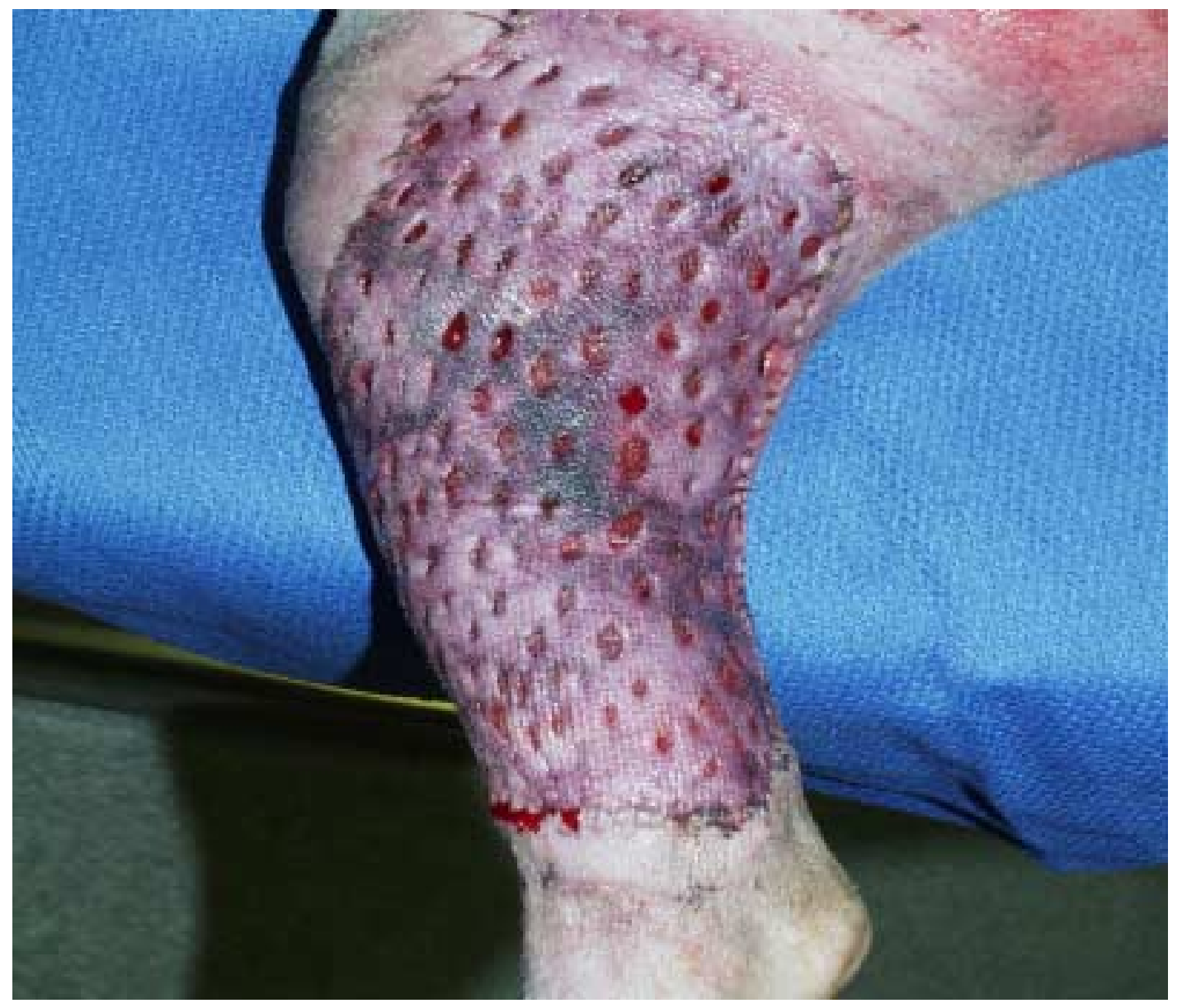

Figure 4 - Day Three Bandage Change - Note skin graft discoloration with multifocal areas of pale pink, red, and dark purple. Mild to moderate bruising was visualized along the cutaneous margin peripheral to the skin grafts. Pink to red bleeding muscle was clearly visible through the fenestrations of the skin grafts in all dogs. All grafts appeared moderately edematous. 


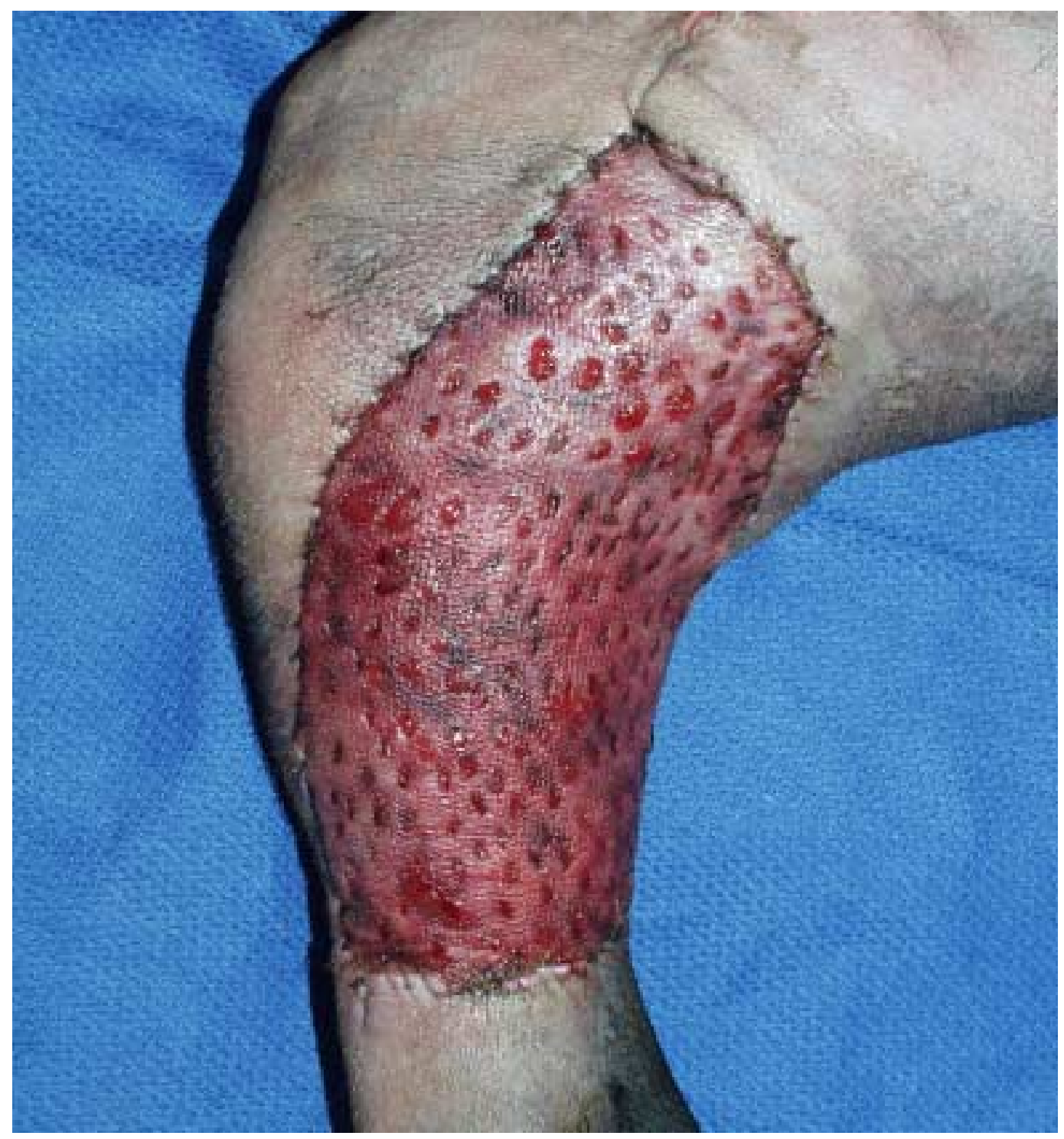

Figure 5 - Day Six Bandage Change - Note cutaneous bruising peripheral to the skin grafts had resolved. The skin grafts developed a more homogenous pink to red coloration. The rectus abdominis muscle was no longer clearly visualized through the fenestrations of the skin grafts in most dogs. 


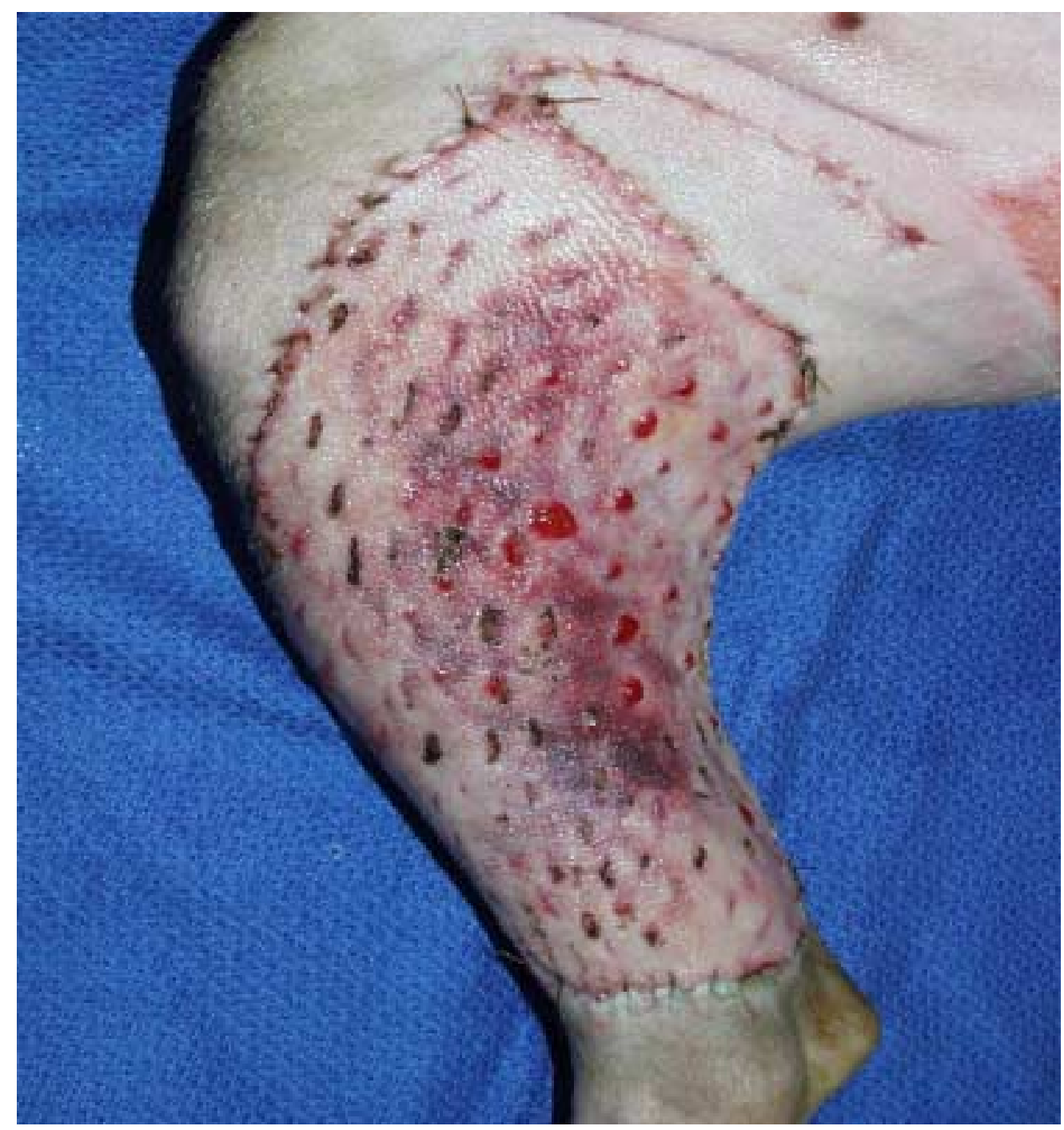

Figure 6 - Day Ten Bandage Change - The skin grafts had similar coloration to surrounding skin but were slightly erythematous. The edema had decreased and the skin grafts were only minimally raised in comparison with surrounding skin. Most skin graft fenestrations had closed and bleeding granulation tissue was visualized protruding from the fenestrations that had not closed. 


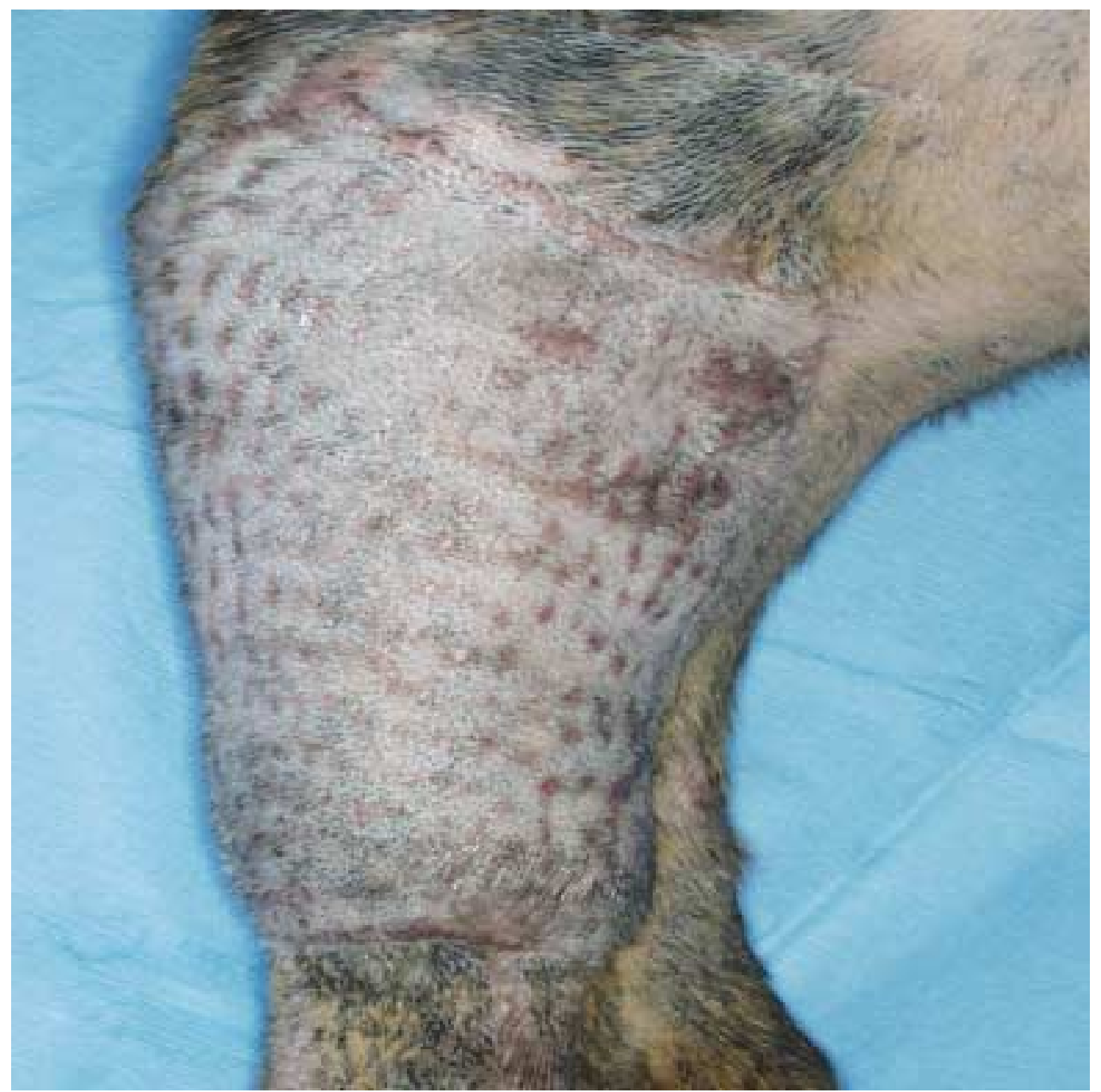

Figure 7 - Grafts at Study Conclusion - The grafts had a similar appearance to surrounding normal skin and moderate hair growth was visualized in all dogs. Hair density varied between individual dogs. Fenestrations of the skin grafts were not readily apparent. The skin grafts were only minimally raised in comparison to surrounding tissues. 


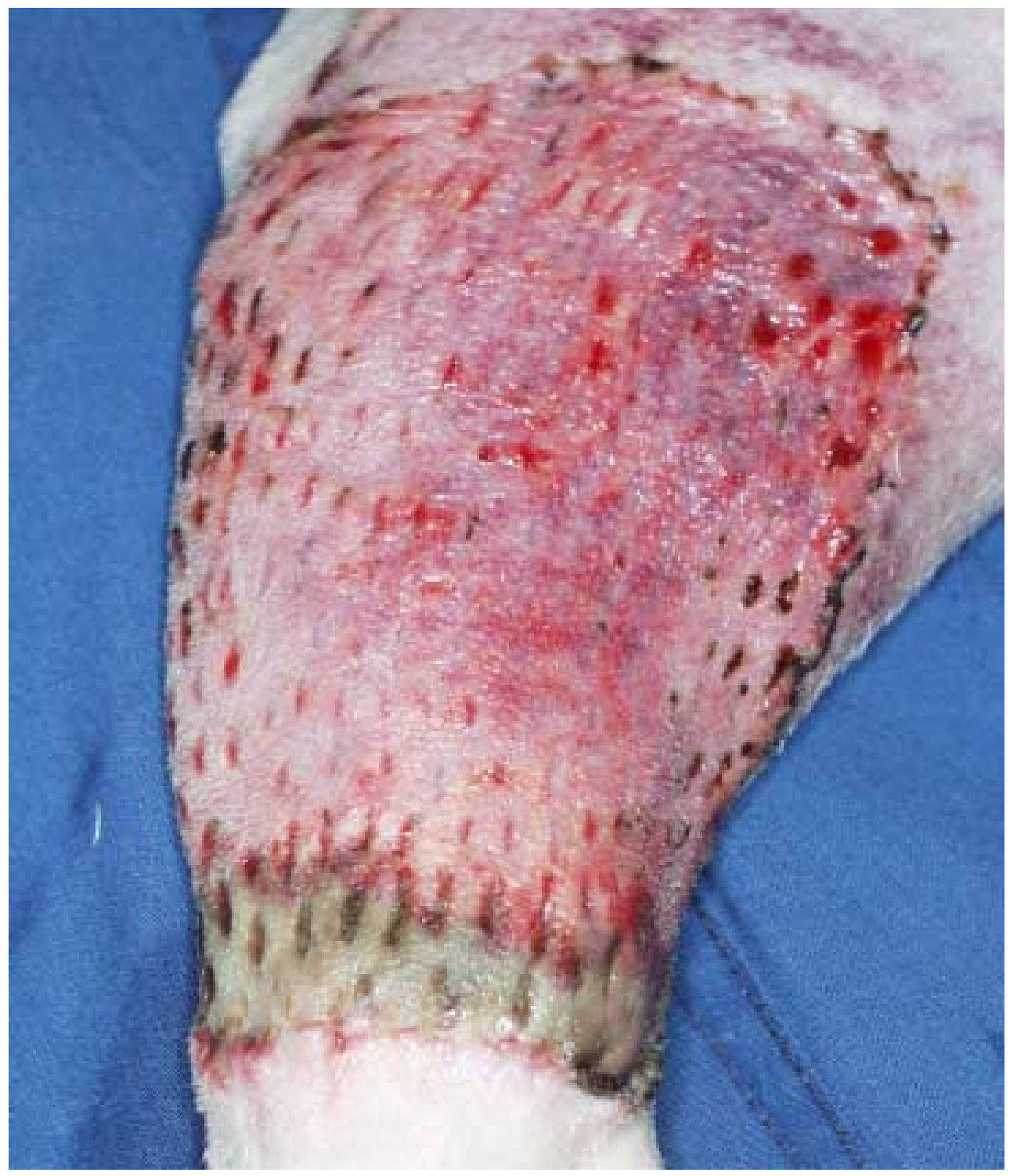

Figure 8 - Distal Graft Necrosis - At post-operative day six in this dog skin graft necrosis was visualized as a line of clear color demarcation. The area of distal discoloration eventually sloughed and was in the process of healing by second intention at the studies conclusion. 


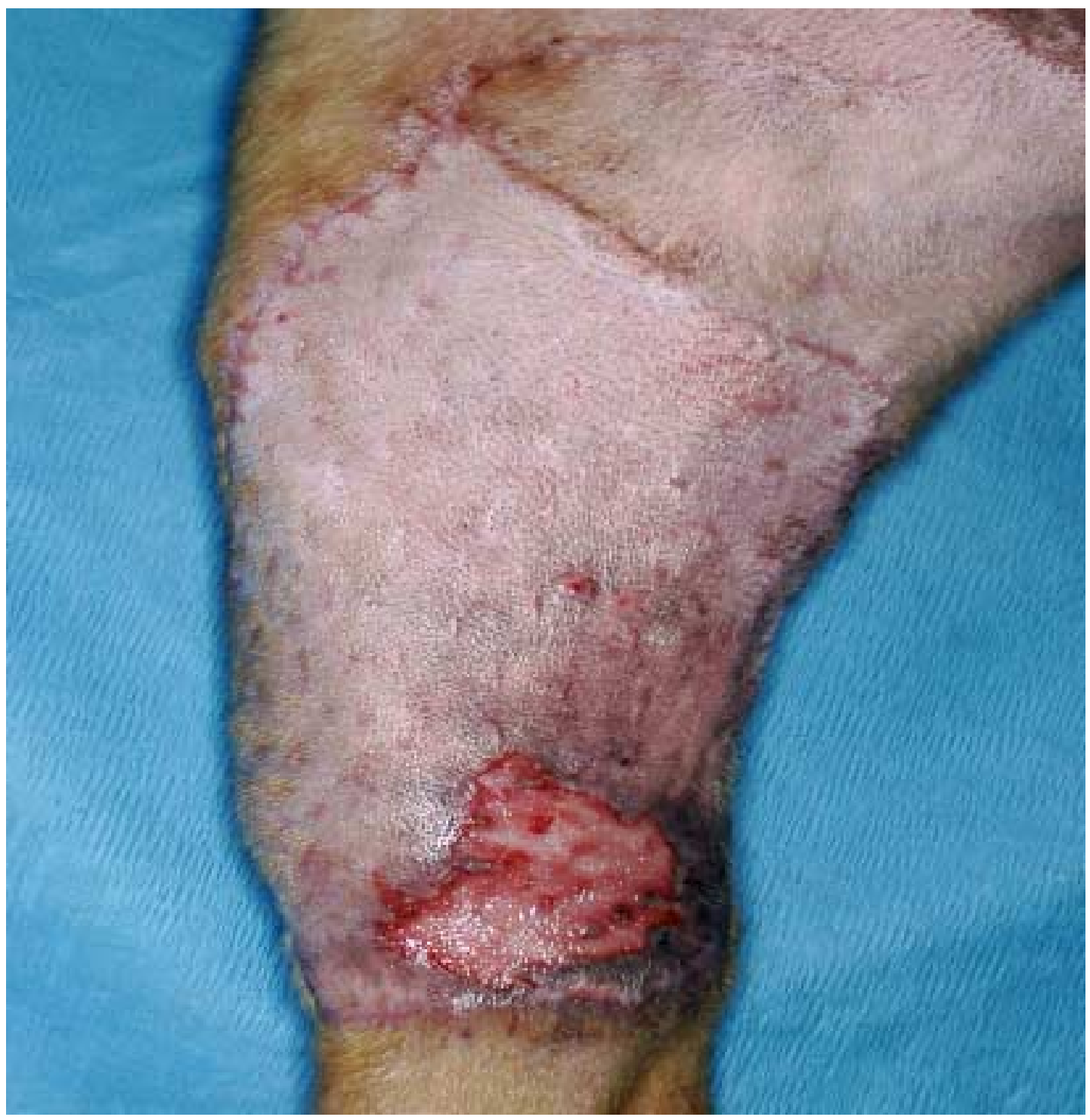

Figure 9 - Traumatic Distal Graft Necrosis - Twenty days after surgery, this dog self traumatized the distal one-third of the skin graft. The damage was superficial and did not expose underlying muscle. At the end of the study, the traumatized area had decreased in size and peripheral epithelium was advancing to close the epidermal defect. Viability of underlying muscle was confirmed at necropsy. 


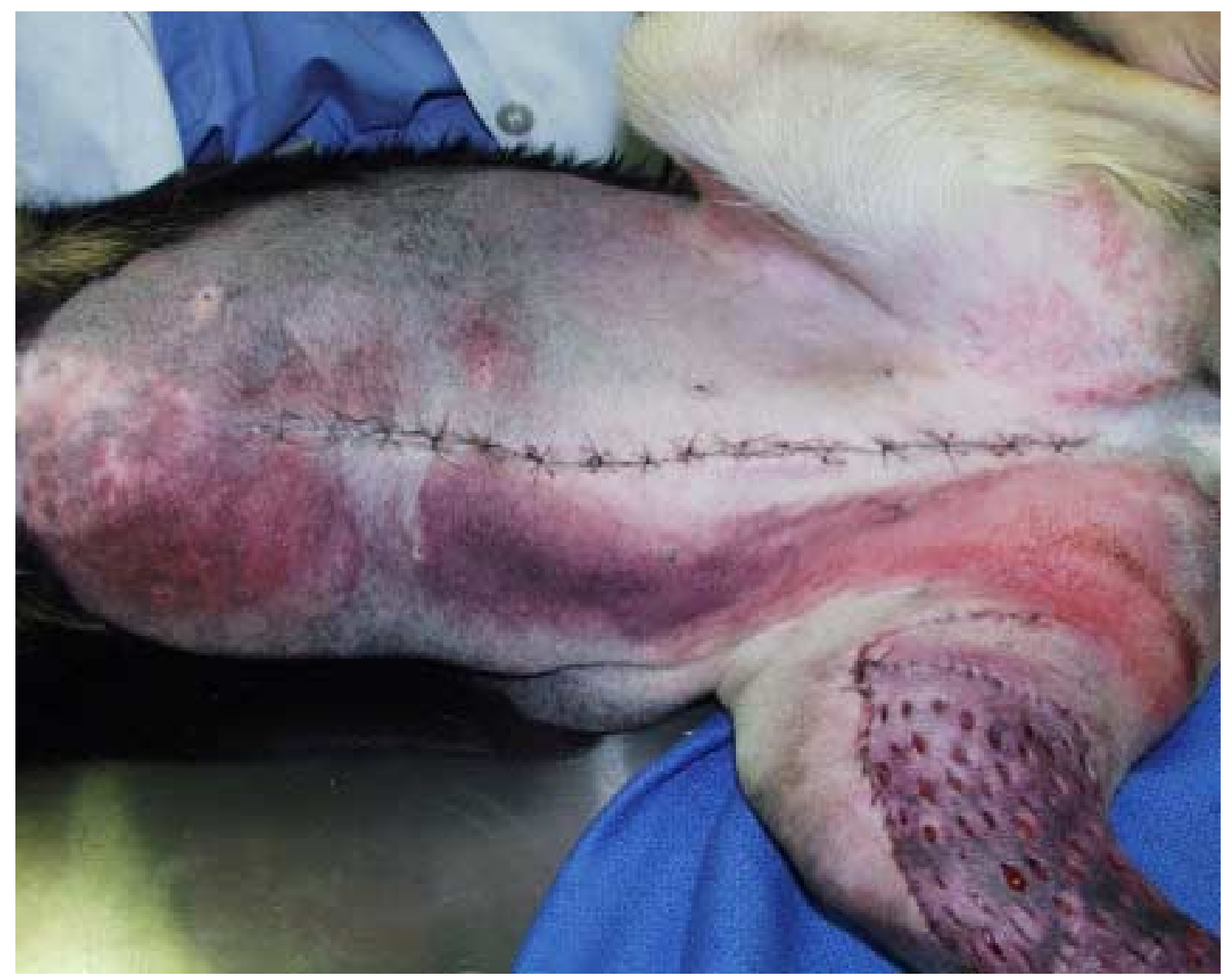

Figure 10 - Incisional Bruising - Donor sites healed without complications in all dogs. Three dogs developed moderate bruising along the cutaneous margins of the abdominal incisions. At necropsy, visual inspection and digital palpation confirmed the integrity of all abdominal closures 


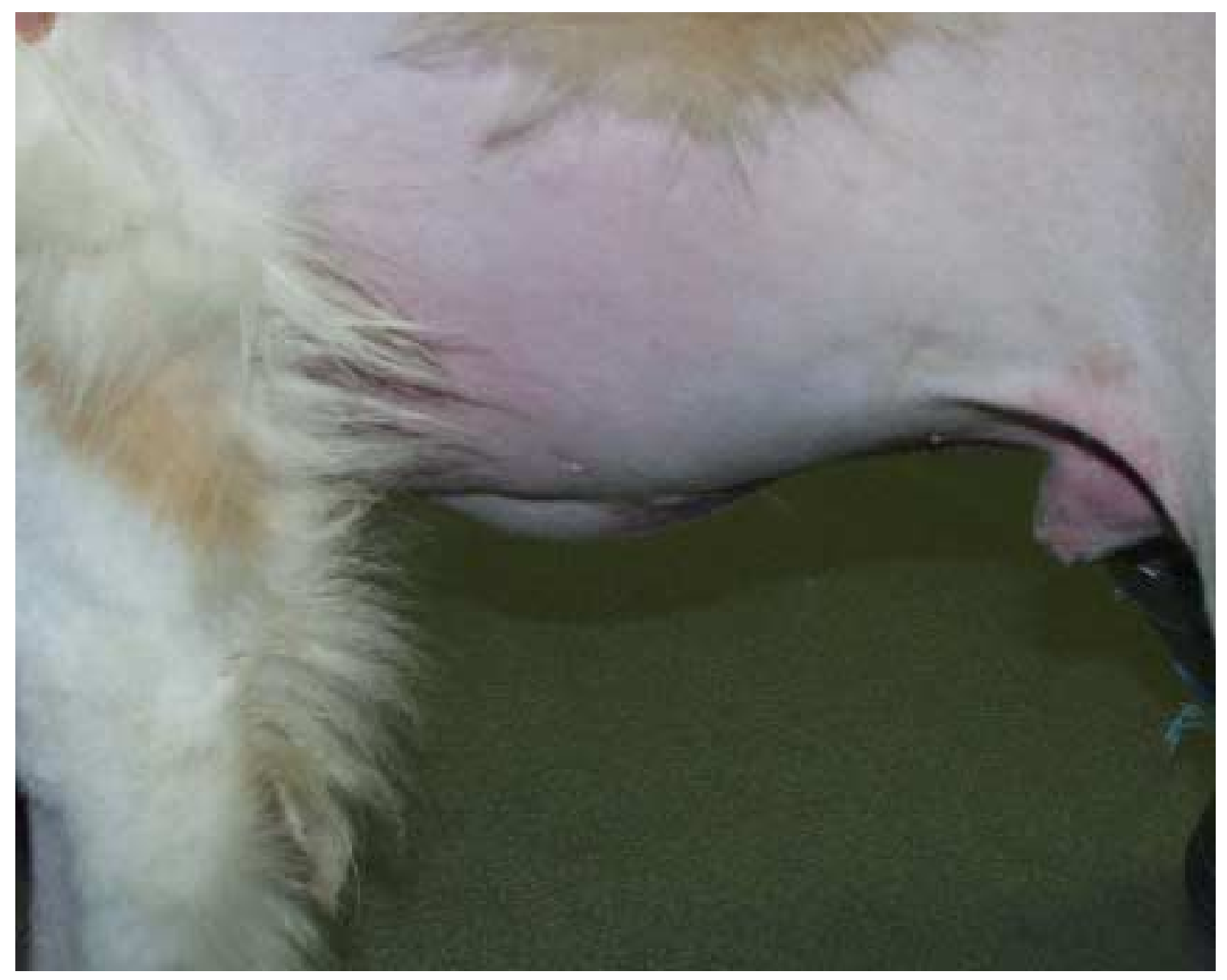

Figure 11 - Seroma Formation - Donor sites healed without complications in all dogs. This dog developed a dependent seroma along its abdominal incision that resolved with no specific treatment within 10 days after surgery. At necropsy, visual inspection and digital palpation confirmed the integrity of all abdominal closures. 


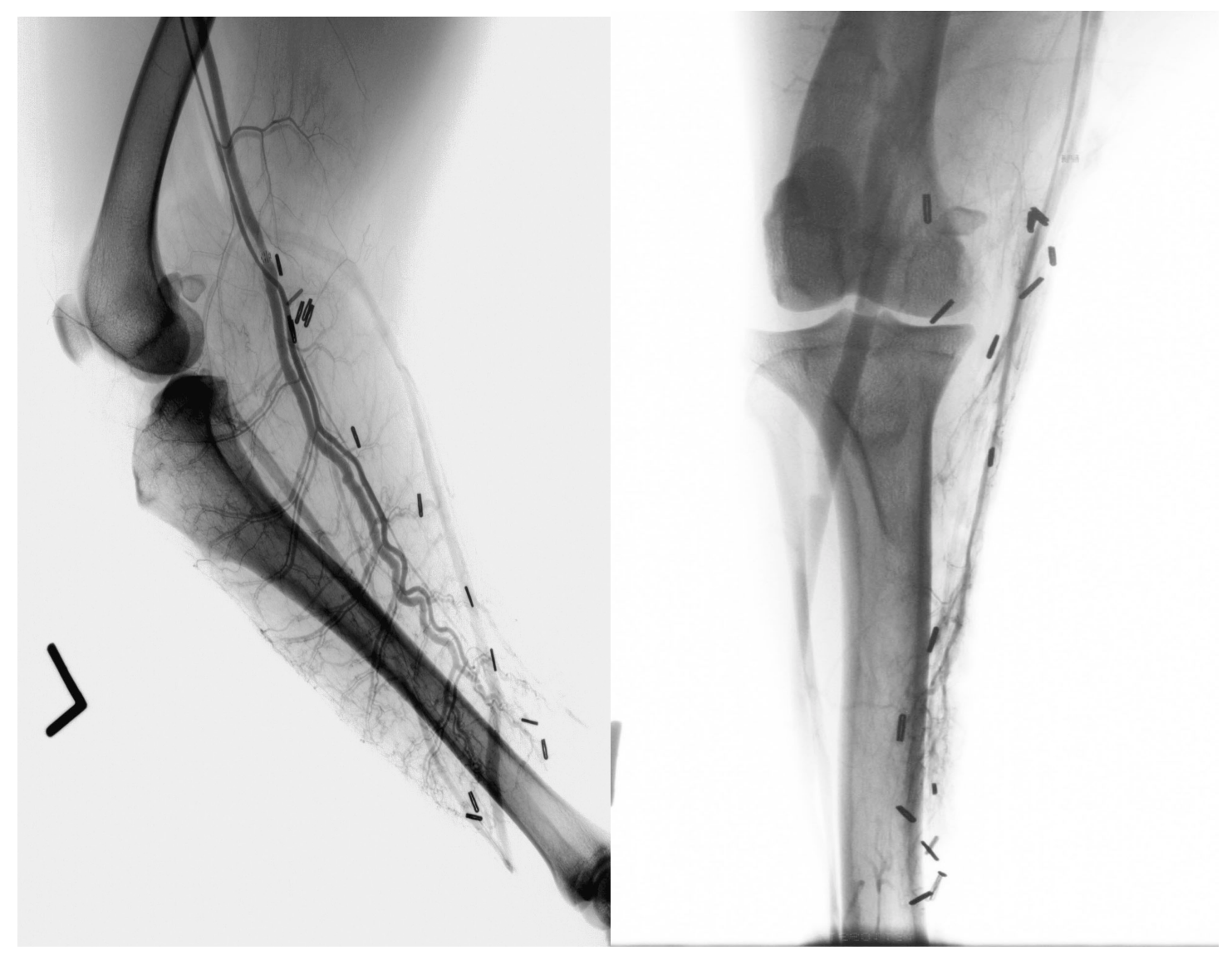

Figure 12 - Phase Two Angiograms - (Craniocaudal and lateral views) Three to five cranial and caudal vascular branches were visualized distal to the level of the anastomoses. The cranial vascular branches were generally larger with more extensive branching than the caudal branches (left image). The angiograms of three dogs revealed the development of vascular anastomoses with peripheral tissues. Anastomotic vessels were visualized between the vascular beds of the transferred rectus abdominis muscles and venous structures of the lateral saphenous vasculature. Contrast is visible within the lateral saphenous vasculature of this dog on both the lateral and craniocaudal views. 


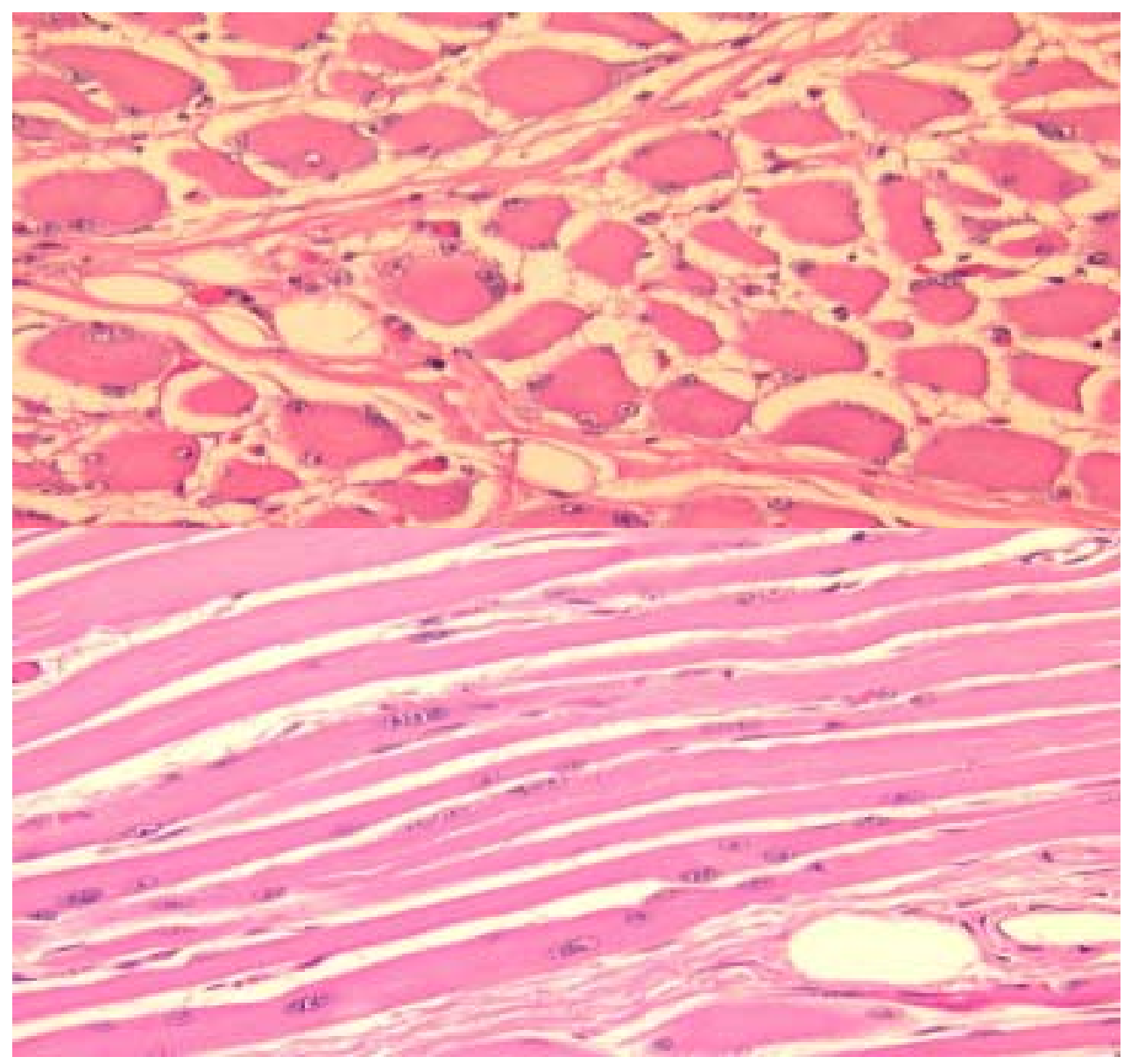

Figure 13 - Histopathologic Muscle Atrophy - Histological evaluation confirmed muscular viability after free tissue transfer in all dogs. All dogs had evidence of mild to moderate muscle atrophy. Enlarged and rounded nuclei were visible both peripherally and occasionally centrally in individual muscle fibers as seen in the bottom image (longitudinal view). Occasional centrally located nuclear rows were present in longitudinal sections of the transferred muscles as well. Increased prominence of spacing around individual muscle fibers and enlarged peripherally located nuclei are seen on the top image (cross-sectional view). These changes are all consistent with neurogenic muscle atrophy. 


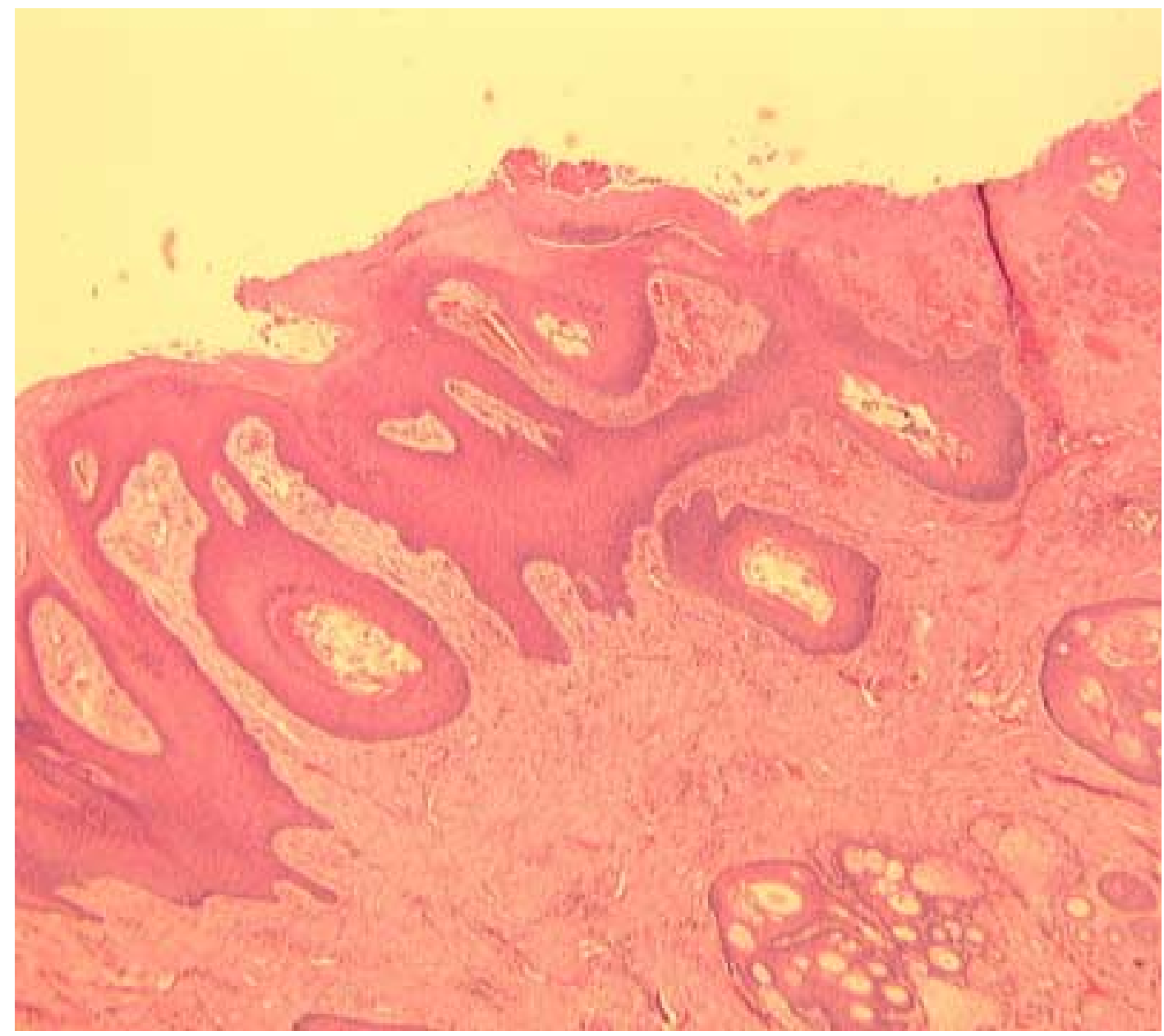

Figure 14 - Distal Skin Graft Necrosis - In the two dogs that developed epidermal ulceration viable muscle was present beneath the ulcerative beds. Marked acanthosis and hyperkeratosis were visualized at the margins of the ulcers in both dogs but there was maintenance of viable dermis and adnexal structures overlying the supporting muscular beds. 
Table 1 - Physical Characteristics of rectus abdominis muscle, donor and recipient vascular pedicles and recipient site defect

\begin{tabular}{|c|c|c|c|c|}
\hline & $\begin{array}{l}\text { Rectus } \\
\text { abdominis } \\
\text { muscle } \\
\text { (mean in } \\
\text { mm) }\end{array}$ & $\begin{array}{l}\text { Caudal epigastric } \\
\text { vasculature (mean } \\
\text { in } \mathbf{~ m m} \text { ) }\end{array}$ & $\begin{array}{l}\text { Medial saphenous } \\
\text { vasculature } \\
\text { (mean in mm) }\end{array}$ & $\begin{array}{l}\text { Recipient } \\
\text { site defect } \\
\text { (mean in } \\
\text { mm) }\end{array}$ \\
\hline Length & $225+/-48$ & $28+/-2$ & NA & $258+/-10$ \\
\hline Diameter & NA & $\begin{array}{l}1.9+/-0.2 \\
\text { (arterial) } \\
2.9+/-0.5 \\
\text { (venous) }\end{array}$ & $\begin{array}{l}2.1+/-0.4 \\
\text { (arterial) } \\
3.1+/-0.6 \\
\text { (venous) }\end{array}$ & NA \\
\hline Width & $55+/-2$ & NA & NA & $66+/-6$ \\
\hline
\end{tabular}




\section{Earl F. Calfee III (Trey)}

\section{VITA}

Earl F. Calfee III (Trey) was born on August 7,1971 in Cleveland, TN. He attended high school in his hometown at Cleveland High School then spent two years at Cleveland State Community College. He earned a Bachelor of Science Degree from the University of Tennessee in Knoxville in 1993. He attained his Doctorate of Veterinary Medicine from the University of Tennessee College of Veterinary Medicine in 1998. He then spent one year in a rotating small animal internship in Boston, MA at the Angell Memorial Animal Hospital. In 1998, he began a small animal surgical residency and master's program at the VA-MD Regional College of Veterinary Medicine in Blacksburg, VA. He is currently in the third and final year of his residency training, which will be completed in July of 2002. 